\title{
Autophagy in thyroid cancer: present knowledge and future perspectives
}

\section{Romana T. Netea-Maier, Viola Klück, Theo S. Plantinga and Johannes W. A. Smit*}

Department of Medicine, Division of Endocrinology, Radboud University Nijmegen Medical Center, Nijmegen, Netherlands

Edited by:

Gabriella Castoria, S.U.N.-II University of Naples, Italy

\section{Reviewed by:}

Federica Barbieri, University of

Genova, Italy

Wen Zhou, Columbia University, USA

\section{*Correspondence:}

Johannes W. A. Smit, Department of Medicine, Division of Endocrinology,

Radboud University Nijmegen

Medical Center, Geert Grooteplein 8

PO Box 9101, Nijmegen 6500 HB,

Netherlands

e-mail: jan.smit@radboudumcn.nl
Thyroid cancer is the most common endocrine malignancy. Despite having a good prognosis in the majority of cases, when the tumor is dedifferentiated it does no longer respond to conventional treatment with radioactive iodine, the prognosis worsens significantly. Treatment options for advanced, dedifferentiated disease are limited and do not cure the disease. Autophagy, a process of self-digestion in which damaged molecules or organelles are degraded and recycled, has emerged as an important player in the pathogenesis of different diseases, including cancer. The role of autophagy in thyroid cancer pathogenesis is not yet elucidated. However, the available data indicate that autophagy is involved in several steps of thyroid tumor initiation and progression as well as in therapy resistance and therefore could be exploited for therapeutic applications. The present review summarizes the most recent data on the role of autophagy in the pathogenesis of thyroid cancer and we will provide a perspective on how this process can be targeted for potential therapeutic approaches and could be further explored in the context of multimodality treatment in cancer and personalized medicine.

Keywords: autophagy, thyroid, carcinoma, therapy, pathogenesis

\section{INTRODUCTION}

Thyroid carcinoma (TC) is the most common endocrine malignancy accounting for $>90 \%$ of malignancies of endocrine glands (1). Worldwide, the incidence of TC has increased, which can be explained by the more intensive use of imaging modalities that increased the detection of small, non-symptomatic tumors (2). Differentiated thyroid carcinoma (DTC), which is the most prevalent TC, has an excellent 10-year prognosis of around $85 \%$ (3). Effective treatment in most DTC patients consists of total thyroidectomy followed by therapy with radioactive iodide (RAI), which is based on the unique ability of follicular thyroid cells to take up iodine via the sodium-iodide symporter protein (NIS) (4). Although prognosis of DTC is favorable, unfortunately, in a high proportion of patients with metastases, the capacity for RAI accumulation is diminished or lost.

\section{THYROID CANCER PATHOLOGY AND MOLECULAR \\ PATHOGENESIS}

Thyroid carcinomas are categorized into three groups. DTC (97\%) and anaplastic thyroid carcinoma (ATC) (1\%) originate from follicular epithelial cells, whereas medullary thyroid carcinoma (2\%) (MTC) originates from neuroendocrine parafollicular cells. DTC can be distinguished in many histological subtypes, major groups being papillary thyroid carcinoma (PTC), which is the most common type of TC (87\%), and follicular thyroid carcinoma (FTC) (6\%). Hürthle cell carcinomas (3-4\%) form a distinct subgroup of DTC that are mostly FTC but can also be PTC. Mixed FTC and PTC also occur.

The genetic events involved in DTC include several gene rearrangements and gene mutations. As a consequence of these genetic mutations and/or rearrangements, signaling pathways are activated in favor of cell growth, survival, and angiogenesis. PTC frequently harbor point mutations of BRAF (30-69\%) and rearrangements in the RET oncogene (40-70\%) leading to MAPkinase pathway activation (5-8). To a lesser extent, RAS gene mutations also occur in PTC (10-20\%). FTC frequently harbor RAS mutations (18-52\%) and/or PPAR $\gamma /$ PAX8 rearrangements (25-56\%) (9). Mutations of PTEN may also be present in FTC. RAS mutations constitutively activate both MAPK and PI3K/AKT signaling pathways. Genetic alterations involving the PI3K/AKT signaling pathway are rare in DTC. In ATC, genetic alterations in the PI3K/AKT signaling pathway may be present (10-12). Also, mutations of the p53 tumor suppressor gene (13) are involved. Recently, mutations in the $\beta$-catenin gene have been described in TC (13-16).

\section{DEDIFFERENTIATION}

Differentiated thyroid carcinoma initially retains the biological properties of normal thyroid cells [iodide uptake by NIS, thyroglobulin (Tg) synthesis, expression of thyroid peroxidase (TPO), and receptor for thyrotropin (TSHR) (17-19)]. However, NIS, TPO, Tg, and TSHR expression gradually decrease in DTC with NIS and TPO disappearing at an earlier stage than others (20-23). Most studies showed reduction or even absence of NIS mRNA in TCs (24-26), while immunohistochemistry studies have demonstrated that NIS protein is overexpressed in many thyroid tumors and is predominantly located in the cytoplasm $(17,21,24)$. TSHR expression is persistent in nearly all DTC $(21,24,27-29)$. Tg production remains preserved even in absence of iodide uptake. In ATC, Tg secretion may decrease and is eventually lost $(21,24$, $27,29)$. A causal relationship between genetic alterations and loss of functional NIS expression is present: tumor cells harboring 
BRAFV600E mutation have decreased NIS, TPO, and TSHR gene expression compared to other tumor cells without this mutation (24, 30-34). In addition, a relationship between activation of PI3K and mammalian target of rapamycin (mTOR) and loss of NIS expression has also been described (35).

\section{INITIAL THERAPY}

According to the consensus of the American Thyroid Association (ATA) $(36,37)$, with the exception of small unilateral PTC, most patients with DTC should be subjected to initial therapy consisting of near-total thyroidectomy followed by RAI remnant ablation therapy. In recent years, the benefits of RAI ablation therapy are debated and a strategy based on risk of recurrence is recommended (37). Recent landmark studies (ESTAMIBL and HiLo) have indicated that $37 \mathrm{mCi}$ is as efficacious as $100 \mathrm{mCi}$ for thyroid remnant ablation (37-39).

\section{RECURRENT OR PERSISTENT DISEASE}

When a malignant lesion is accessible, surgery can be performed. If a malignant lesion is present, which cannot be cured by surgery, RAI therapy may be performed. The remission rate in pulmonary metastases treated with RAI varies from $90 \%$ in patients with microscopic metastases to $10 \%$ in macroscopic metastatic disease and from 20 to $7 \%$ in bone metastases (37, $40,41)$. Palliative therapies include external irradiation, radiofrequency ablation, chemoembolization and for pulmonary metastases, endobronchial laser therapy (42-45). Approximately 5-15\% of DTC patients will develop or present with local recurrent disease or metastasis. In $25-66 \%$ of these patients, the susceptibility to RAI is diminished or lost $(3,37,46)$.

Treatment options for patients with RAI resistance were until recently limited to palliative treatment, as conventional chemotherapy is not effective in DTC. Recently, novel treatment options have become available in terms of kinase inhibitors (KIs).

The DECISION trial, with sorafenib, was the first phase III study with a kinase inhibitor in DTC (46) and showed a reduction in progression free survival (PFS) of 5 months. A phase III study with lenvatinib (SELECT study) showed a reduction in PFS of 14.7 months (47). In addition to multi-kinase inhibitors (MKI), compounds have been developed the selectively target mutated kinases. Both studies have shown for the first time that MKI have a benefit on PFS in patients with advanced DTC. However, these drugs are only effective in subgroups of patients and most effects are temporary. Therefore, additional approaches are warranted. Study of pathogenetic mechanisms in DTC may reveal novel targets for therapy. Autophagy has emerged during the last years as an important player in the pathogenesis of TC.

\section{AUTOPHAGY AND CANCER}

An increasing body of literature supports the central role of autophagy in cancer development from initiation to progression and metastasis, including TC. Autophagy ("self-digestion") is an evolutionarily conserved mechanism present in all eukaryotic cells, essential for maintaining cell homeostasis and adaptation to various stress situations including metabolic and oxidative stress resulting from nutrient deprivation or hypoxia (48). In this process, in conditions of cellular stress often resulting in excessive production of damaged proteins or organelles and reactive oxygen species (ROS), a double layer membrane is generated in the cytoplasm that engulfs defective or toxic molecules and organelles to form an autophagosome. After fusion with the lysosomes and release of lysosomal acid enzymes in the vesicle, these molecules undergo enzymatic digestion and the resulting products are either removed from the cells or are made available for synthesis of new proteins or organelles. This process is also known as macroautophagy (henceforth referred to as "autophagy"). In addition to macroautophagy, microautophagy has also been described, referring to the process of self-digestion in which no autophagosome is formed and the molecules compelled for degradation are engulfed by the lysosomes through invagination of lysosomal membrane. Furthermore, soluble proteins can be shuttled into the lysosome via the lysosomal chaperone proteins, a process termed chaperone-mediated autophagy (48).

Autophagy involves several Atg (autophagy) proteins, encoded by ATG genes. The function and the structure of these proteins have been initially and extensively studied in yeast species (49). However, for the majority of these proteins human orthologs have been found as well. A schematic representation of the process of autophagy is presented in Figure 1. The regulation of autophagy is very complex and not completely understood. One of the central molecules involved in the regulation of autophagy is the mTOR, which is a very potent inhibitor of autophagy (50). Moreover mTOR is involved in a complex network of signaling pathways that control and link a number of other fundamental cellular processes including cell metabolism, differentiation, proliferation, and cell survival $(51,52)$. The mTOR kinase activates multiple pathways that favor cellular proliferation and inhibits the autophagy pathway, thereby preventing cell cycle arrest. Furthermore, mTOR induces a metabolic shift toward glycolysis in both aerobic and anaerobic microenvironments, also known as the Warburg effect, to enable proliferation at higher rates and in hypoxic conditions, respectively (53).

Several studies link autophagy to cancer. It has been shown that autophagy can have either a positive or a negative effect on cancer development and progression depending on tumor type and stage of the disease. This apparently dual position is not completely understood but it seems to reflect the complex effect of autophagy on several fundamental processes such as cell survival, cell death, senescence, cellular metabolism, and inflammation in the context of continuous external changes in the tumor microenvironment. The role of autophagy in TC is largely unexplored. The evidence is only scarce and fragmented. Nevertheless, there are clear indications that autophagy is involved in several steps of thyroid tumorigenesis and progression as well as in therapy resistance and therefore could be exploited for therapeutic applications. In the present review, we will summarize the most recent data on the role of autophagy in the pathogenesis of TC and we will provide a perspective on how this process can be targeted for potential therapeutic approaches in TC.

\section{AUTOPHAGY AND TUMOR INITIATION}

In basal conditions, autophagy is fundamentally involved in maintaining the cellular homeostasis. In pathological conditions inducing cellular stress, autophagy is upregulated primarily for cytoprotective purposes. In this case, incapacity of the cells to 


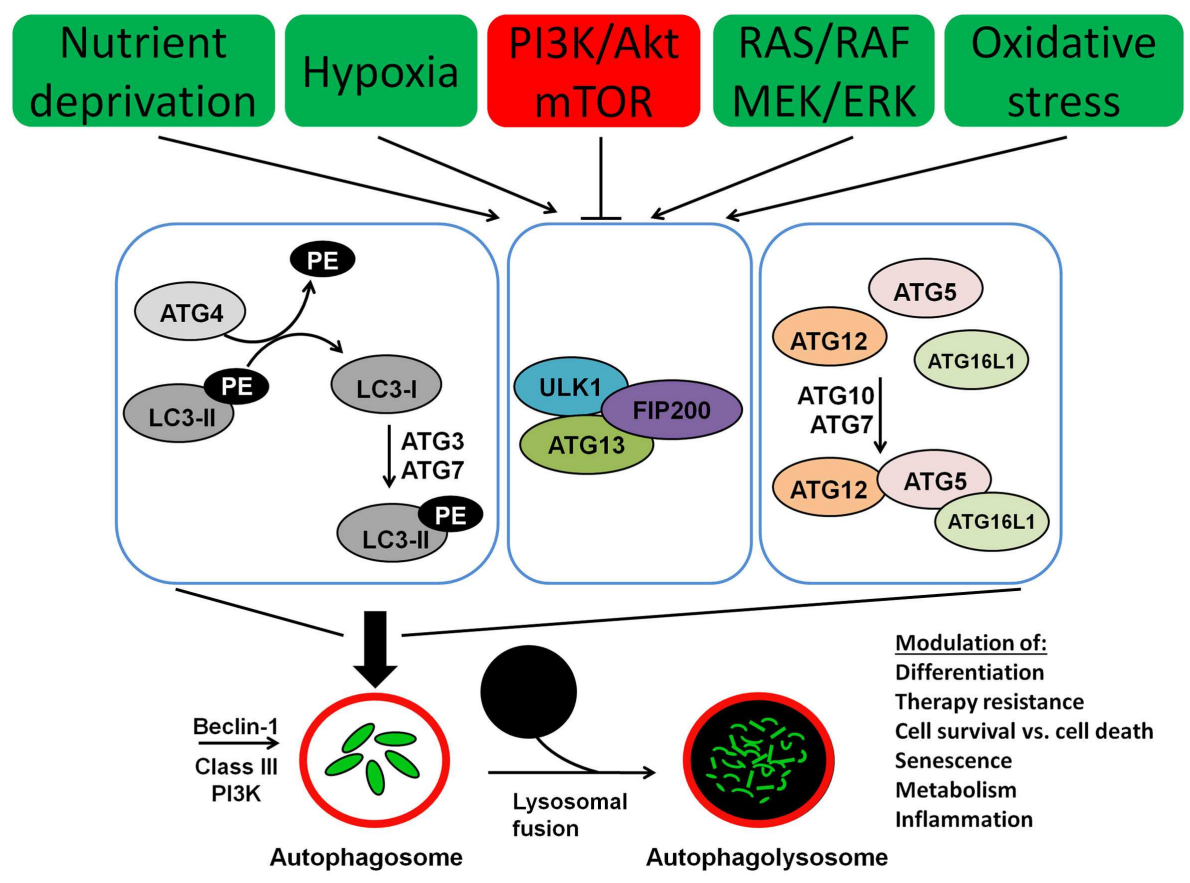

FIGURE 1 | Molecular machinery of autophagosome assembly and Iysosomal fusion. Beclin 1 is part of the type III PI3K complex that initiates autophagosome formation. Two ubiquitin-like systems are required for formation of the isolation membrane; (I) coupling of LC3 (ATG8) to phosphatidylethanolamine (PE) and (II) conjugation of ATG12 to ATG5 and ATG16L1. The five C-terminal amino acids of LC3 (unconjugated LC3-I) are cleaved of by ATG4, which is required to link the protein after activation by ATG7 and ligation by ATG3 to PE in the autophagosomal membrane (conjugated LC3-II). Similarly, ATG7 and ATG10 couple ATG12 to ATG5 and ATG16L1. This complex then localizes to the outer membrane of the forming autophagosome. Autophagosomes then fuse with lysosomes for degradation of their cargo. upregulate autophagy, for instance, due to defective ATG genes, can result in accumulation of defective molecules or excessive ROS, which impair the function of cells and DNA stability resulting in disease (54).

Several mechanisms have been suggested through which autophagy might exert its tumor suppressive effects. Autophagy has a crucial role in maintaining DNA stability. As a result of oncogene activation, defective organelles produce high amounts of ROS, which when accumulated in large amounts induce oxidative stress and contribute to additional DNA damage. Autophagy represents the major buffer mechanism activated to counteract this excessive ROS production by removal of defective organelles such as mitochondria as a main source of excessive ROS through a process of selective mitophagy. In addition, autophagy contributes to the quality control of the protein synthesis. Related to this, autophagy has an important role in the clearance of defective p62, a ubiquitin-binding protein that is produced in response to metabolic stress. It has been shown that tumor cells in which the autophagy mechanism is defective accumulate excessive amounts of p62, sufficient to cause dysregulations of NF-kB signaling, accumulation of ROS and DNA damage (55). Several studies suggest that in the early phases of cancer development autophagy fulfills primarily a tumor suppressive role.

Beclin 1, encoded by the BECL1 gene located on chromosome $17 q 21$, is a key molecule involved in the initiation of autophagy and phagophore formation. Previous studies have shown that in autophagy-deficient mice due to monoallelic deletion of BECL1 develop spontaneously malignant tumors (56). Therefore, BECL 1 is considered as a haplo-insufficient tumor suppressor gene. Moreover, somatic monoallelic deletions of BECL1 stimulate development of Hepatitis-B-induced premalignant liver lesions (56). In addition to that, monoallelic deletions of BECL1 have been found in a significant percentage of human cancers, including breast cancer, melanoma, ovary, and prostate (57-60). Furthermore, an increased Beclin 1 expression has been associated with a favorable prognosis in several cancers (60-62). In TC, however, Li et al. have found by immunohistochemistry in samples from 86 patients with PTC (57 with lymph node metastases) that Beclin 1 expression was increased in $88 \%$ of the PTC tissue samples and in $98 \%$ metastatic lymph nodes whereas in the paired normal thyroid tissues and lymph nodes without metastases from the same patients the expression of Beclin 1 was only low or absent (63). The authors suggest that Beclin 1 neo-expression correlate with the tumorigenesis and lymph node metastasis in TC. However, the mutation status of the tumors is not mentioned in this study though may be relevant for the interpretation of these data. It is known that up to $75 \%$ of PTCs carry somatic mutations in the BRAF gene, in particular the V600E BRAF (5-8). Presence of BRAF mutations has also been associated with an increased risk for lymph node metastasis in PTC. Furthermore, it has been shown that in melanoma, BRAF mutations induce autophagy (64). Therefore, whether the observed increased expression of Beclin 1 and 
possibly the activation of autophagy in the study of Li et al. is the cause or the consequence of the malignant process, it is not clear. In addition, it has to be mentioned that the function of Beclin 1 is complex and reaches beyond autophagy, including the link between autophagy and apoptosis $(65,66)$. Therefore, although the exact role of Beclin 1 in the development of TC is not known, these data suggest that autophagy is involved in the pathogenesis of TC.

Besides Beclin1, other autophagy-related proteins such as Atg4c, Atg5, and Atg7 also were found to have tumor suppressor functions in mice models and mutations autophagy-related genes such as ATG2B, ATG5, ATG9B, ATG 12, and UVRAG have been described in gastrointestinal cancers as well $(67,68)$. Furthermore, mice lacking Parkin, which is important for the ubiquitination of proteins on mitochondria contributing to the initiation of selective autophagy of damaged mitochondria, show a procarcinogenic phenotype $(69,70)$. With respect to TC, a recent study suggests that patients carrying the ATG5 single nucleotide polymorphisms rs2245214 have a higher probability to develop TC. However, no other ATG genetic variants investigated in this study showed a significant association with TC susceptibility. Furthermore, none of the selected genetic variants were associated with clinical parameters of disease progression and outcome (71).

Altogether, these studies support in part a tumor suppressive role of autophagy at least in some tumor types. In this setting, one might speculate that pharmacological induction of autophagy at least in some autophagy-deficient cells might be beneficial in the early stages of carcinogenesis. Nevertheless, none of the previous studies has established a clear causal relationship between deficient autophagy and tumorigenesis. Interestingly, other autophagydeficient mouse models, such as the Ulk1- or Nix-deficient mice have not been shown to have an increased risk of spontaneous malignancies $(72,73)$. Others, such as the FIP200-deficient mice that lack an important autophagy gene have an impaired tumorigenesis (74). Moreover, Beclin 1 deficiency is often associated with p53 deficiency suggesting that the function of these two proteins is interrelated (59). Therefore, although autophagy may play an important role in tumor initiation, this is not the only mechanism involved in this process and its effect probably depends on the integrity and activation of other biological processes as well, such as apoptosis.

Another mechanism through which autophagy may be involved in tumorigenesis involves its regulation by other oncogenes and tumor suppressor genes. Figure 2 depicts the main pathways involved in thyroid carcinogenesis and their link with autophagy. Oncogenes such as Akt and class I PI3K inhibit autophagy whereas tumor suppressor genes such as PTEN and p53 can stimulate autophagy. Interestingly, germ-line mutations in PTEN cause a syndrome characterized by increased risk to develop malignant tumors including follicular thyroid neoplasia and FTC (75). Several somatic mutations that play an important role in thyroid cell malignant transformation can influence autophagy either positively or negatively. BRAF mutations that can be found in the majority of PTC are known to activate autophagy in melanoma (76) but possibly also in PTC (77). On the other hand, activation of PI3K/Akt/mTOR pathway (78), which has been found to be more common in ATC than in DTC (79) as well as in more aggressive tumors $(80,81)$, sometimes in combination with BRAF or RAS

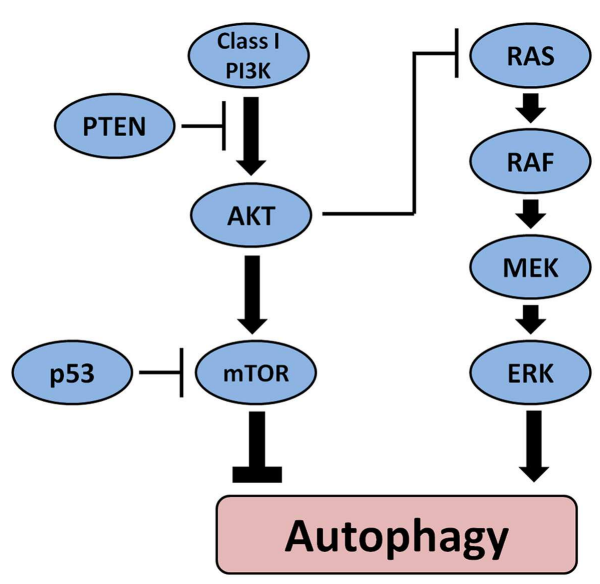

FIGURE 2 |The main pathways involved in the pathogenesis of thyroid cancer and their effect on autophagy. Oncogenes such as Akt and class I PI3K inhibit autophagy whereas tumor suppressor PTEN and p53 can stimulate autophagy. BRAF mutations that can be found in the majority of PTC activate autophagy.

mutations (79) is associated with inhibition of autophagy. Also, inactivating mutations in the PTEN tumor suppressor gene leading to activation of the PI3K-Akt pathways have been found more often in advanced TC (82). This data suggest that in TC, they may represent late events resulting in progression to more aggressive forms. Through its position at the crossroads between the MAPK and the PI3K/Akt/mTOR pathway, RAS can play a dual role in the regulation of autophagy. It can either stimulate autophagy when the MAPK is selectively activated or inhibit autophagy through activation of PI3K pathway. Therefore, when the autophagy machinery is intact, the role of autophagy as a tumor suppressor or tumor promotor may depend apart from the histological tumor type also on the presence of certain mutations in oncogenes or tumor suppressive genes and/or the accumulation of mutations in the tumor during cancer development and progression.

\section{AUTOPHAGY AND TUMOR PROGRESSION}

Once the carcinogenic phenotype has been established, autophagy plays a role in maintaining the malignant phenotype and in tumor progression through its effect on cell metabolism, cell survival, and cell death on one hand, and on the immune response in the tumor microenvironment on the other hand. In other words, the role of autophagy in tumor progression is largely dependent on the crosstalk between autophagy and other fundamental biological processes of apoptosis, senescence, immune response, and inflammation. The rapidly multiplying tumor cells rely on autophagy to maintain an increased proliferation rate in an unfavorable microenvironment characterized by hypoxia, insufficient nutrients delivery, and oxidative stress. As a result of these unfavorable conditions or as a direct effect of the oncogenic mutations, tumor cells switch for their energy metabolism to aerobic glycolysis (Warburg effect). Interestingly, as shown above, the same mutations, such as PI3k/Akt/mTOR, also inhibit the autophagy. In the context of restrictive nutrients delivery, this deficient autophagy can result in apoptotic-deficient tumor cells in increased cell death 
through necrosis due to the fact that the cancer cells are unable to meet the increased metabolic energy demands (83). In contrast to apoptotic cells, cells that die through necrosis, through ruptures of their plasma membrane, release several proinflammatory molecules, the damage-associated molecular patterns (DAMPs), such as uric acid, ATP/UTP, high mobility group B1 (HMGB1), in their microenvironment. These molecules help recruit and activate macrophages and other antigen presenting cells, such as dendritic cells (DC), and trigger adaptive immune responses and cytokine production that create a pro-tumorigenic environment in the peritumoral stroma, which can result in angiogenesis, tumor progression, and metastasis. In addition, both antigen presentation and antigen recognition that represent the cornerstone of this immune response are dependent on the integrity of the autophagy machinery. In this respect, it has been shown that autophagy facilitates antigen presentation by tumor cells, such as human embryonic kidney cells (HEK293T) and melanoma cells, thereby facilitating the recognition of these cells by the immune system, facilitating the removal of these cells (84). Another mechanism through which autophagy, through crosstalk with inflammation, can contribute to tumor progression is by facilitating the cellular senescence. In this process, senescent cells that are characterized by a sustained cell arrest produce cytokines that promote recruitment of immune cells that are ultimately responsible for the removal of the senescent cells but also can facilitate the tumor progression (85). Therefore, in addition to its role in maintaining the metabolic homeostasis, cellular integrity and function, and in cell survival and cell death, autophagy contributes to shaping the immune response in the tumor microenvironment.

The tumor necrosis factor (TNF) family comprises several ligands, among which TNF-related apoptosis-inducing ligand (TRAIL), which trigger apoptosis and has been shown to potently and selectively kill TC cells (86). Investigation of TRAIL has attracted attention in cancer therapy studies because they contribute to the immune cell-mediated cytotoxicity and because recombinant ligands are available for pharmacological use. Nonetheless, treatment with TRAIL has been hampered with significant therapy resistance in several cancers, including TC. It has been shown that T-helper 1-type cytokines, such as interferon (IFN)-gamma, TNF-alpha, and IL-1 beta increase the sensitivity of both normal and neoplastic thyrocytes to TRAIL. However, IGFI and other growth/survival factors produced in the local tumor microenvironment activate the PI3K/Akt pathway, exert an antiapoptotic effect, and are also known to inhibit autophagy through mTOR $(86,87)$. Recently, Jin et al. has shown that in PTC cell line TPC-1 harboring RET/PTC1 rearrangement, TRIAL treatment induced activation of autophagy and apoptosis whereas blocking autophagy using ATG7 siRNA abrogated this effect (88). In the same study, in the ATC cell line FRO, treatment with TRAIL did not induce the autophagy and blocking the autophagy with ATG siRNA sensitized FRO cells to TRAIL-induced apoptosis. Therefore, both the PTC and the ATC might benefit from modulation of autophagy. However, depending on the type of tumor and the mutation status of the tumor, either stimulation or inhibition of autophagy may be beneficial.

To add to the complexity of the role of autophagy in cell death, it has been shown that despite its primary cytoprotective functions in response to various forms of stress in normal cells, when activated excessively, it is believed that autophagy can contribute to cell death. In this case, it has been suggested that, uncontrolled excessive autophagy, such as results from overexpression of Beclin 1 in mammalian cells (89), might result in cell death through either stimulation of apoptosis (90) or massive uncontrolled, possibly selective, self-digestion of cytoplasmic components beyond repair that render the cell unviable (91). Clearly, several arguments support the link between autophagy and apoptosis. Both processes share common regulatory pathways and effector molecules. Both can exert an either positive or negative effect on each other and sometimes activation of both may coexist in the same tumor. However, the majority of studies supporting the autophagy-dependent cell death were performed in cells deficient in apoptosis (91), suggesting that autophagy represents only a non-canonical pathway leading to cell death. The exact regulatory mechanisms that influence the equilibrium between apoptosis and autophagy and ultimately determine cell fate, either cell death or survival, remain elusive.

The results of a few recent studies support the role of autophagy-dependent cell death in TC. Reversine, a synthetic purine analog has been shown to induce apoptosis and cell cycle arrest in differentiated and poorly differentiated TC both in vitro and in vivo in mouse xenograft models (92). Lu et al. (93) showed that reversine was also able to induce phagosome formation in WRO cells in a dose-dependent manner possibly through the Akt/mTOR/p70S6K pathway that was suppressed after exposure to reversine. Another argument to support the crosstalk between autophagy and apoptosis is provided by the studies on the antitumoral effects of statins. Zeybek et al. showed that in PTC and normal thyroid cell lines treatment with rosuvastatin, the statin inhibited the cell proliferation and induced cell death in a dose-dependent manner. In this study, autophagy was particularly activated in the BC-PAP cell line (BRAF V600E positive) at lower doses whereas at higher doses induction of apoptosis was predominant (94). Furthermore, Lopergolo et al. investigated whether the combination therapy with the RET-targeting tyrosine kinase inhibitor sunitinib and cisplatin can enhance apoptosis in MTC cell lines harboring the RET M918T oncogene and xenograft mouse model (95). The authors found that sunitinib induced a severe autophagosome accumulation and lysosomal dysfunction and cisplatin induced additional lysosomal leakage. Combination therapy resulted in more apoptotic cell death and a better response in xenograft mouse model with MTC.

The relation between cancer cell metabolism and its impact on cell survival, proliferation, and autophagy in TC has only scarcely been studied. In a recent study, Morani et al. have investigated the impact of PTEN deficiency and mutant p53 on glucose metabolism in two TC cell lines, the FTC133 (PTEN null, p53 mutated) and WRO (wild type 553 and PTEN). They have found that the FTC133 cell line that display impaired apoptosis and reduced autophagy due to the somatic mutations in PTEN and p53 were clearly more sensitive to glucose restriction than the WRO cells in which glucose deprivation was able to stimulate autophagy and therefore offer the cells an escape route to prolonged survival (96). This is clearly in line with the other studies showing that in apoptosis, deficient tumor cells that are depending for the increased 
energy requirements on an increased influx of glucose for glycolysis, maintaining an intact or an increased autophagy response is crucial for cell survival in conditions of nutrients deprivation. Defects in autophagy, such as those resulting from concomitant mutations in the PTEN or PI3K/Akt pathway render the cells more sensitive to glucose depletion. This phenomenon could potentially be explored for therapeutic tumor starvation strategies in TC.

\section{AUTOPHAGY AND TUMOR INVASION AND METASTASIS}

The role of autophagy in tumor invasion and metastasis is less known. The epithelial-to-mesenchymal transition (EMT) represents an important step to invasion and metastasis. In this process that enables detachment of the cells from their natural environment tumor cells gain properties including enhanced plasticity that favors survival and metastasis and induce resistance to cytotoxic agents and radiotherapy. In this context, it has been found that autophagy is involved in the regulation of cell plasticity (97). In addition, it helps preventing anoikis (cell death after the cell has been detached from its extracellular matrix) and therefore promoting survival of cells that have been detached form their extracellular matrix (98). Furthermore, induction of autophagy in breast carcinoma cells has been shown to induce EMT and resistance to cytotoxic T-cell-mediated lysis, therefore targeting autophagy may potentially avoid the occurrence of this resistance (99). Interestingly in this context, Meng et al. reported recently that knockdown of BAG3, a protein involved in multicellular pathways, induces EMT in thyroid cells through activation of a E-cadherin suppressor, ZEB1 (100). Furthermore, BAG3 has been found to be involved in Beclin1-independent autophagy (non-canonical autophagy) (101). Li et al. found that Earle's balanced salt solution (EBSS) starvation reduced the BAG3 expression in vitro in thyroid cells and that forced BAG3 expression suppressed autophagy and promoted the apoptosis in TC cells exposed to EBSS starvation, making the BAG3 an interesting potential target to be further explored for therapy (102). In another recent publication, Wang et al. have investigated the effects of long non-coding DNA (lncRNAs) on TC cells in vitro (77). The BRAF-activated lncRNAs (BANCR), which are novel regulators implicated in cancer biology, have also been shown to be overexpressed and involved in cell migration in melanoma. BANCR has also been shown to induce EMT in malignant tumors such as melanoma, colon cancer, and non-small cell lung cancer (103-105). The BANCR were overexpressed in four of the five investigated tissue samples of PTC and in IHH-4 PTC cell line compared to the normal thyroid tissue. Overexpressed BANCR markedly activated autophagy and inhibited apoptosis in the PTC cell line. Inhibition of autophagy abrogated the effects of BANCR on cell proliferation. In this study, there were no evident effects of BANCR on the cell migration in the TC cells. Therefore, although some studies suggest that autophagy may play a role in tumor invasion and metastasis, its place in the pathogenesis of TC is not well defined. Further studies to elucidate this process may uncover novel therapeutic strategies.

\section{AUTOPHAGY AND RESPONSE TO THERAPY}

Several studies have implicated autophagy in the tumor response and resistance to therapy with either ionizing radiation or other cytotoxic agents. It has been shown that treatment with ionizing radiation is associated with a strong induction of autophagy and this may contribute to cell survival and the acquired resistance to therapy in many cancer cells including breast, nasopharyngeal, pancreatic cancer, and malignant glioma (106-110). For this reason, inhibition of autophagy with chloroquine or hydroxychloroquine in combination with radiotherapy or chemotherapy has been investigated as a strategy to prevent therapy resistance and sensitize tumors to therapy. This, however, does not seem to be the case in TC. Yeung et al. published in 2007 the first observation on autophagy and TC in relation to therapy (111). In this study, the authors observed in a mouse xenograft model obtained with ARO and KAT4 ATC cell lines increased macroautophagy in the tumors from the mice treated with the antiangiogenic agent Combretastatin A4 phosphate. The authors suspected that this is likely explained by the induction of autophagy due to anoxia and starvation resulting from therapeutic vascular disruption in this model. A few years later, Lin et al. found that doxorubicine and radiation also induced autophagy in both human PTC samples and PTC cell lines (112). However inhibition of autophagy with 3-methyladenine (3 MA) decreased the radiosensitivity and chemosensitivity of the TC cells, suggesting that at least for the therapy resistant PTC stimulation of autophagy may be a potential therapeutic strategy. In line with this hypothesis, Lin et al. showed that stimulation of autophagy using the mTOR-inhibitor everolimus resulted in sensitization of PTC cells to both doxorubicin and radiation. Furthermore, the effects of everolimus and doxorubicin as radiosensitizers were synergistic. The authors suggest that the autophagy-dependent cell death, as detailed in the previous paragraph, mediated through Met kinase is the main mechanism behind these effects (113). Treatment with everolimus has also been shown to potentiate the activity of sorafenib and sunitinib, two MKI that target particularly the VEGF and the MAPK in MTC through induction of autophagy (114). Therefore, in contrast to other cancer, although treatment with both chemotherapy and radiotherapy were shown to induce autophagy in TC cells, the TC seem to profit from the synergistic activation of autophagy, possibly through mechanisms related to autophagic cell death to increase their sensitivity to the cytotoxic agents.

Radiotherapy and chemotherapy also induce oxidative stress and result in cell death. Interestingly, autophagy has been shown to play an important role in the response to chemotherapy of some tumors, in particular through influencing the immune response in the tumor microenvironment. It is known that treatment with chemotherapy can induce immunogenic cell death. In other words, as a result of treatment with chemotherapeutic agents, a succession of processes takes place resulting in apoptosis and necrosis. As a consequence, membrane exposure of calreticulin and release of other proteins such as HMGB1 and ATP takes place that in turn have the ability to attract and recruit antigen presenting cells such as macrophages and DC in the tumor microenvironment. The DCs engulf the damaged tumor cells (remnants) and through antigen-presentation activate T-cells that in turn exert an antitumoral effect on the remaining unaffected cancer cells, thus enhancing the antitumoral effect of the chemotherapeutic agent. In TC, it has been reported that treatment with selumetinib and IFN gamma increased the immunogenicity of PTC cell through increased HLA-ABC expression and was associated with 
increased T-cell activation and IL2 production by peripheral blood leukocytes co-cultured with treated PTC cell lines (115). Michaud et al. has shown in cell lines and mouse models that particularly the ATP release by the chemotherapy-induced dying tumor cells is highly dependent on the integrity of autophagy and is required to induce an antitumoral immunogenic response (116). In this study, autophagy-deficient tumors released significantly lower amounts of ATP and were not able to elicit antitumoral immunogenic responses in response to therapy with methotrexate. The immunogenicity of the autophagy-deficient cells could be restored when treated with ARL67156, an inhibitor of ectoATPases that increased the extracellular ATP concentrations and when treated with recombinant human IL-1 $\beta$, whose production depends on the availability of ATP. Furthermore, when treated with methotrexate in vivo in immunocompetent mice, only the growth of autophagy-competent tumors could be reduced as compared to the autophagy-deficient tumors. In contrast, there was similar lack of response to treatment of these tumors in immunodeficient mice, regardless the autophagy status. This suggests that the immunogenic response is an essential contributor to the efficacy of chemotherapy and that this response is highly dependent on the integrity of the autophagy pathway.

Autophagy has also been linked to response to treatment with proteasome inhibitors. Autophagy is closely related to the ubiquitin-proteasomes system (UPS), the other main intracellular protein degradation pathway within the eukaryotic cells (117). Proteasome inhibitors, including the multipathway inhibitor bortezomib, are promising agents for treatment of highly aggressive cancer (118). Studies performed on several cancer cell lines demonstrated that autophagy inhibitors can synergize with the cytotoxic effects of the proteasome inhibitors (119-121). Based on these preclinical data, a number of trials investigating autophagy inhibition in combination with proteasome inhibitors have been initiated. In TC, Zhang et al. found that proteasome inhibitors induced a decrease in Beclin 1 expression (122). However, the exposure to proteasome inhibitors caused beclin 1-independent macroautophagic cytotoxic responses in TC cells. In this context, in TC cells Beclin 1 was able to potentiate the antitumoral effects of the proteasome inhibitors in an autophagy-independent manner via survivin and suppressin.

An important mechanism contributing to therapeutic resistance of cancer cells involves activation of pathways that confer stem cell-like characteristics onto cancer cells $(123,124)$. This process is strongly linked to EMT, which promotes cell survival and invasiveness, resulting in more aggressive tumor phenotype. Recent studies suggest a link between the EMT, stem cell-like characteristics, autophagy, and resistance to cytotoxic agents $(97,99)$. Hinterseher et al. reported a clear expression of hedgehog pathway signaling factors, which are involved in the survival of stem cells, in two ATC cell lines (Hth 74, C643) and in primary tumor samples (125). Moreover, treatment of these cell lines with the hedgehog inhibitor cyclopamine showed a time- and dose-dependent inhibition of cell growth. Activation of hedgehog pathway has also been reported in MTC (126). Inhibition of hedgehog pathway has been shown to activate autophagy (127). Therefore, exploring how modulation of autophagy in this context may help prevent therapeutic resistance is warranted.
Summarizing these data, modulation of autophagy has the potential to synergize and contribute to the effect of other cytotoxic treatments and reduce resistance to treatment, which should be further explored in the context of multimodality treatment in cancer and personalized medicine.

\section{IMPLICATIONS FOR THERAPY}

\section{IMPLICATIONS OF TARGETING AUTOPHAGY FOR THYROID CANCER THERAPY: PRECLINICAL STUDIES}

Genetic alterations in the PI3K/Akt/mTOR pathway cause an addiction to this pathway in TC cells and create sensitivity to inhibition by targeting players in this pathway, such as Akt and mTOR (128). Among these, mTOR is of particular interest due to its involvement in the control of cell proliferation. Inhibitors of mTOR such as rapamycin, everolimus, and temsirolimus have all been shown to inhibit tumor cell proliferation in several cellular models. Rapamycin effectively inhibits proliferation and induces apoptosis of SW579 cells. Furthermore, the invasive ability of SW579 cells decreased when treated with rapamycin. In contrast, no obvious changes were observed in the expression of Akt indicating that there might be a feedback loop effect by mTOR inhibition (129).

RAD001 (everolimus) is an orally bioavailable inhibitor of the mTOR pathway. Papewalis et al. demonstrated that RAD001 inhibits cell growth in ATC cell lines (130). Also temsirolimus, a specific mTOR inhibitor showed the potency of suppressing growth in several cell lines that harbored genetic alterations in the $\mathrm{PI} 3 \mathrm{~K} / \mathrm{Akt} / \mathrm{mTOR}$ pathway with $\mathrm{IC}_{50}$ (concentration at which $50 \%$ inhibition occurs) in the nanomolar range (128).

Mammalian target of rapamycin exists in two different complexes, mTORC1 and mTORC2, which could both be targeted by potential anti-cancer agents. Rapamycin inhibits the mTORC1 complex, but not the mTORC2 complex (131). The general view is that mTORC2 regulates Akt and, as a consequence of only targeting mTORC1 activity, it has been shown that drug resistance quickly develops due to compensatory activation of Akt $(132,133)$. Therefore, it seems essential to target both the mTOR complexes for desired anti-cancer effects (134). In the last few years, several mTOR ATP-competitive inhibitors have been reported acting upon mTOR in both complexes and showing a more complete anti-cancer activity in comparison with that of rapamycin and its derivatives (135). These new mTOR inhibitors provide a method to avoid the feedback up-regulation of p-AKT observed with mTORC1 inhibitors (136). For example, INK128, a dual mTORC1 and mTORC2 kinase inhibitor, inhibited growth at low nanomolar concentrations in cell lines and 5-week-old Tg-RET/PTC3 mice treated with $3 \mathrm{mg} / \mathrm{kg}$ for 2 weeks displayed a reduced proliferation index (136). Treatment with Torin2, another second-generation mTOR inhibitor, inhibited cell viability and induced caspase-dependent apoptosis via activation of mitochondrial apoptotic pathway in PTC cells. In addition, on PTC xenograft tumor growth in nude mice Torin2 treatment induces anti-cancer effects (137).

Another way to avoid the negative feedback loop in mTORC2 is to directly inhibit Akt. KP372-1, an Akt inhibitor, blocked signaling downstream of Akt in thyroid tumor cells, leading to inhibition of cell proliferation and increased apoptosis. The major advantage 
of KP372-1 over Wortmannin and LY294002 as PI3K inhibitors is its greater efficacy and the marked induction of apoptosis in cancer cell lines. This may be due to its targeting a central downstream molecule and also due to the potential for a number of processes to bypass effects at the level of PI3K (138). Moreover, in vivo use of LY294002 in mice has been associated with many adverse effects, including death (139). Similarly, Wortmannin has demonstrated hepatic and hematopoietic toxicity (140). Therefore, although Wortmannin and LY294002 inhibit the PI3K/Akt pathway, their drawbacks raise concerns about their suitability as leading candidates for further development as anti-cancer drug. However, despite its greater efficacy, a potential downside of Akt inhibitors is toxicity because of the importance of Akt signaling in many normal cellular processes such as insulin signaling, and the lack of selectivity of the current Akt inhibitors including KP372-1 to different Akt isoforms (138).

Over the years, several new and selective Akt inhibitors have been developed. MK2206 is a recently developed novel non-ATPcompetitive allosteric Akt inhibitor. Liu et al. tested the therapeutic potential of MK2206 for TC using various TC cells with known genotypes in the PI3K/Akt pathway. They demonstrated its potent and efficacious inhibition of proliferation with $\mathrm{IC}_{50}$ values in the low micromolar range, mostly below or around $0.5 \mu \mathrm{M}$, of TC cells that harbored mutations in the PI3K/Akt pathway (141). Although Akt inhibitors show effect in different cell lines, they are less potent as a single-drug than mTOR inhibitors. A prior report demonstrated that the presence of genetic alterations of PTEN, PIK3CA, and Aktl correlated well with sensitivity to an Akt inhibitor, but had weaker correlations with the sensitivity to an mTOR inhibitor (128). This discrepancy suggests that mTOR activity does not depend solely on PI3K/Akt activity and may explain the lower efficacy of Akt inhibitors in comparison with mTOR inhibitors.

\section{IMPLICATIONS OF TARGETING AUTOPHAGY FOR THYROID CANCER THERAPY: CLINICAL STUDIES}

Novel small-molecule protein-KIs have shown promising results in clinical trials on thyroid cancer, including axitibib (142), sorafenib (143), motesanib (144), and pazopanib (145). These KI mainly target the RAS-RAF-MEK-ERK pathway and prevent angiogenesis by inhibiting vascular endothelial growth factor receptors. KIs that inhibit the PI3K/Akt/mTOR pathway are less common, but the rapamycin analog everolimus, has recently been shown to have potential in clinical trials.

Lim et al. (146) published the first clinical trial of the activity of everolimus in patients with progressive, locally advanced or RAI refractory TC including all histologic subtypes. The primary end point was disease control rate, defined as partial response and stable disease $\geq 12$ weeks. The patients self-administered everolimus $10 \mathrm{mg}$ orally once daily until unacceptable toxicity or disease progression was reached. Disease control was observed in 31 (81\%) patients and the median PFS was 47 weeks in all patients. However, a confirmed objective response was observed in only two patients $(5 \%)$. Another phase-II trial included patients with metastatic, incurable RAI refractory, and progressive TC who were treated with $10 \mathrm{mg}$ everolimus orally, showed similar results (147). The primary endpoint in this study was PFS. Only one patient experienced a partial response, whereas $18(55 \%)$ and $10(30 \%)$ achieved stable disease lasting 6 and 12 months, respectively. Interestingly, activation of autophagy without markers of apoptosis was detected in three patients subjected to sequential biopsies. It was concluded that the activation of autophagy could account for the higher rate of disease stability.

As KIs are known to induce stable disease only on a temporary basis, several mechanisms contribute to clinical resistance. Carracedo et al. showed that mTORC1 inhibition can activate MAPK through a PI3K-dependent feedback loop in human cancer (148). Activation of a different prosurvival signaling pathway upon mTOR inhibition explains as to why the tumor shows an initial response followed by rapid progression. However, the majority of known mechanisms of clinical resistance involve secondary mutations in the target kinase. Such mutations have been described for ABL, KIT, EGFR, ALK, BRAF, MEK, PDGFRA, FLT3, and ROS1 (149). Recently, evidence was obtained that acquired resistance to mTOR inhibition can occur through these mechanisms (150).

Autophagy inhibition using hydroxychloroquine and other autophagy regulators in combination with different therapeutic strategies has been evaluated in early-phase clinical trials on various types of tumors $(151,152)$. Chloroquine and hydroxychloroquine inhibit autophagy at a late stage by blocking lysosomal acidification resulting in an inability to digest its engulfed cargo. This leads to increased cytotoxicity in combination with several anti-cancer drugs in preclinical models. These results led to multiple early-phase clinical trials in humans, mainly with solid tumors $(151,152)$. Although targeting autophagy in cancer will provide new opportunities for drug development, more potent and specific inhibitors of autophagy are needed. Moreover, the effect of autophagy regulators in TC should be further evaluated.

\section{IMPLICATIONS OF TARGETING AUTOPHAGY FOR THYROID CANCER THERAPY: SYNERGISTIC STRATEGIES}

Several combination therapies of autophagy modulating agents have been examined for their efficacy to inhibit TC progression, invasiveness, and metastatic disease.

\section{Combination therapy: multiple targets within the PI3K/Akt/mTOR pathway}

BEZ235 is a dual PI3K/mTOR inhibitor that reduces PI3K and mTOR kinase activity by competitive binding to the ATP-binding cleft of these enzymes (153). BEZ235 effectively inhibited cell proliferation in eight $\mathrm{TC}$ cell lines originating from four major histological types (PTC, FTC, poorly differentiated TC, ATC) with relatively low median effect doses $(<44 \mathrm{nmol} / \mathrm{L})$. In addition to inhibiting cell cycle progression, BEZ235 caused apoptosis in two out of six cell lines. Daily treatment in mice with 8505-C xenograft tumors delayed tumor growth during the therapeutic period and significantly degraded caspase-3, indicating that this compound may induce apoptosis in vivo (154). However, reactivated tumor growth observed after discontinuation of BEZ235 suggests that prolonged treatment is necessary to maintain therapeutic effect. However, BEZ235 was not able to repress p-Akt in all cell lines, indicating that the compensatory activation of Akt by inhibiting mTORC1 may still play a role (148). The novel allosteric Akt inhibitor MK2206 could completely overrule the feedback activation of Akt from temsirolimus-induced mTOR suppression, 
and the two inhibitors synergistically inhibited TC cell growth in OCUT1 and K1 cell lines (141).

\section{Combination therapy: concomitant targeting PI3K/Akt/mTOR and other pathways}

The involvement of multiple signaling pathways in aggressive TC suggests that it may be necessary to target several pathways simultaneously for effective treatment. Jin et al. demonstrated over $60 \%$ growth inhibition with combined MEK and mTOR inhibition in 10 cell lines using the MEK inhibitor AZD6244 (ARRY-142886) and mTOR inhibitor rapamycin (155). Recently, a combination of AZD6244 and GDC0941, a novel PI3K inhibitor, led to synergistic inhibition of TC cells that harbored genetic alterations in MAPK and PI3K/AKT pathways. Exposure to the combination of the compounds caused DNA fragmentations, which indicates strong apoptosis (156). These proapoptotic effects are essential since cell death is fundamental for eradication and hence cure of cancer. Other combination therapy also includes blocking VEGFR. RAF265 is an ATP-competitive pan RAF-inhibitor that also inhibits VEGFR2. RAF265 and BEZ235 strongly inhibit tumor growth, both in vitro and in vivo (157). The tested drug combination resulted in profound G1-G0 arrest and was associated with consistent inhibition of targeted kinases. These preclinical studies provide further support that dual targeting of the MAPK and PI3K pathways is more effective than targeting pathways individually. Sorafenib is an oral $\mathrm{KI}$ with in vitro activity against multiple targets, including RAF, RET, VEGFR1, and VEGFR2. An ongoing phase-II trial (NCT01141309) assesses the combination of sorafenib ( $400 \mathrm{mg}$ twice a day) and everolimus ( $10 \mathrm{mg}$ daily) in progressive RAI-refractory TC, excluding ATC. The combination of sorafenib and everolimus shows promising results: partial response rates were higher than those reported for sorafenib as a single agent, with a partial response of $56 \%$ for non-medullary TC. However, several grade- 4 adverse events occurred possibly related to the drug (158).

Other phase-II trials are investigating combination therapy of everolimus and pasireotide, a novel somatostatin analog, in adults with RAI refractory DTC (NCT01270321) and sorafenib combined with temsirolimus in patients with TC of follicular cell origin (e.g., PTC, FTC, Hurthle cell carcinoma) (NCT01025453). Furthermore, although not yet investigated in TC, PI3k/Akt/mTOR inhibitors can be combined with autophagy regulators: the PI3KmTOR inhibitor NVP-BEZ235 synergized with chloroquine to induce apoptosis in glioma xenografts (159).

\section{Combination therapy of PI3K/Akt/mTOR inhibitors with conventional radiotherapy and chemotherapy}

As mentioned before, PI3K/Akt/mTOR inhibitors may sensitize TC cells to current therapy by, e.g., inducing redifferentiation, as has been demonstrated for mTOR inhibition (160). Furthermore, external radiotherapy and chemotherapy may be used in extensively dedifferentiated TC. Chemotherapy options include doxorubicin, docetaxel, or the combination of cisplatin with doxorubicin for ATC. Several studies showed the synergistic effect of mTOR inhibition with chemotherapeutic agents; RAD001 (everolimus) sensitized PTC to doxorubicin and external beam radiation in a synergistic fashion. Treatment with
$20 \mathrm{nmol} / \mathrm{L}$ of RAD001 decreased the $\mathrm{IC}_{50}$ of doxorubicin by 48 and $38 \%$ in $8505-\mathrm{C}$ and TPC- 1 cells, respectively, and PTC cells treated with RAD001 had a significant improvement in sensitivity to various doses of radiation (113). Although not yet approved for treating ATC, the combination therapy of BEZ235 and paclitaxel consistently demonstrated synergistic effects against ATC in vitro (154). Interactions between BEZ235 and paclitaxel, irinotecan, and etoposide were determined by calculating the combination index by Chou-Talalay equation. Synergistic effects were identified for the combination of BEZ235 and paclitaxel in all used ATC lines. BEZ235 combined with irinotecan also enhanced therapeutic efficacy, particularly when more cells were affected. BEZ235 plus etoposide only slightly increased cytotoxicity.

Moreover, a phase I study of daily everolimus plus low-dose weekly cisplatin was performed in 30 patients with advanced solid tumors not curable by surgery or radiation therapy, including 7 patients with TC (161). The phase II recommended dose is everolimus $10 \mathrm{mg} /$ day (days 1-21) and cisplatin $20 \mathrm{mg} / \mathrm{m}^{2}$ (days 1,8 , and 15) of a 28 -day cycle, potentially leading to phase-II trials combining everolimus and cisplatin for TC treatment.

\section{TARGETING AUTOPHAGY MODULATORS IN THYROID CANCER: A POTENTIAL REDIFFERENTIATION STRATEGY}

Redifferentiation of TC cells that restores the sensitivity of the tumor to RAI therapy is considered an important potential therapeutic approach. Multiple strategies have been investigated for their potential to induce redifferentiation of TC cells, ranging from non-specific modalities such as retinoic acid and histone modification agents to treatment with specific oncogene-guided KIs, including MAPK, MEK, mTOR, and Akt kinases. Of particular interest to TC, inhibition of mTOR was demonstrated to increase the capacity of physiological thyroid follicular cells to accumulate iodine (35). Also PI3K-inhibition induced sodium iodine symporter (NIS) expression in rat thyroid cells and human PTC (162). By redifferentiation of TC cells, sensitivity to RAI therapy could be restored. Ho et al. reported recently that a short course treatment with selumetinib, a MAPK kinase inhibitor, resulted in an increase of ${ }^{131} \mathrm{I}$ uptake sufficient to enable RAI therapy in 12 of 20 patients (163). Moreover, a similar effect was observed in vitro using an mTOR inhibitor. Pretreatment with rapamycin resulted in three- to fivefold higher amounts of iodine accumulated in both BC-PAP (PTC, BRAF V600 mutated) and FTC133 (FTC, PTEN deficient) cell lines by restoring functional hNIS expression (160). This study provides exciting new findings suggesting that mTOR inhibition, potentially mediated by activation of autophagy, is a promising new target for adjunctive therapy to improve the efficacy of RAI treatment. It is indeed well described that autophagy is also involved in mechanisms that determine the differentiation status of TC cells; active autophagy contributes to maintaining the differentiation status of TC cells after malignant transformation. In contrast, class I PI3K and mTOR block the autophagy process and induce dedifferentiation of TC cells. These effects on the differentiation status of tumor cells are exerted at the level of the functionality of the iodine uptake machinery with NIS expression being one of the most prominently regulated proteins ( 35 , 162). These findings indicate that autophagy is closely related to 
RAI sensitivity, which makes it a promising target to combat RAI resistance. By reasoning, since also starvation is a potent inducer of autophagy, patient starvation using a hypocaloric diet prior to RAI treatment to induce local autophagy activity in thyroid cancer cells might also increase the clinical response to RAI therapy.

\section{CONCLUSION AND PERSPECTIVES}

Remarkable progress in understanding the molecular pathogenesis of TC has been made in recent years. Significant knowledge has been accumulated on the role of fundamental signaling pathways, such as the MAPK and the PI3K/Akt/mTOR pathways. These pathways provide new targets for therapeutic agents. This review focused on novel KI targeting the PI3K/Akt/mTOR and autophagy pathway. Several new KI have been developed of which dual mTORC1 and mTORC2 kinase inhibitors show great potential in different models, whereas classical mTOR inhibitors have already been tested in clinical trials.

Notably, targeting the PI3K/Akt/mTOR pathway is more effective in TC cell lines with mutations in this pathway. PTEN loss of function was, for example, identified as a predictor of sensitivity to mTORC1 inhibition in several cancers (131). Therefore, the concept of personalized medicine can be perfectly applied to patients with TC considering the causal mutations in different pathways described in various types of tumors. The characterization of the mutational profile is critical in the design of treatment with either single agent or combinational therapy and has been demonstrated to lead to more effective treatment in pilot studies $(164,165)$. Consistent with the idea of personalized medicine are findings that combination therapy is more effective in RAI refractory tumors, usually harboring mutations in several pathways, than targeting pathways individually $(154,156)$. Ongoing trials combining KI will reveal their efficacy in the future.

Although the role of autophagy in various settings in TC needs to be further elucidated, autophagy regulators can be of great potential. Induction of autophagy can sensitize thyroid tumor cells to other therapies and plays a major role in the regulation of apoptosis. Combining novel KIs with other cytotoxic therapy is another possible implementation in the development of novel therapeutic strategies for TC, for example, the combination of everolimus and chemotherapy. Moreover, the mTOR inhibitor rapamycin has shown to increase the iodine uptake and may therefore be a promising new target for adjunctive therapy for improving the efficacy of RAI treatments. In the coming years, further developments in treatment options and selective application of available agents are to be expected that will provide novel approaches to more effectively treat TC.

\section{AUTHOR CONTRIBUTIONS}

All authors (RM, VK, TP, JS) had substantial contributions to the conception of paper, reviewing the literature, drafting the manuscript, and revising it critically for important intellectual content. They have all approved the final version of the manuscript.

\section{REFERENCES}

1. van der Zwan JM, Mallone S, van Dijk B, Bielska-Lasota M, Otter R, Foschi R, et al. Carcinoma of endocrine organs: results of the RARECARE project. Eur J Cancer (2012) 48(13):1923-31. doi:10.1016/j.ejca.2012.01.029
2. Chen AY, Jemal A, Ward EM. Increasing incidence of differentiated thyroid cancer in the United States, 1988-2005. Cancer (2009) 115(16):3801-7. doi:10.1002/cncr.24416

3. Brose MS, Smit J, Capdevila J, Elisei R, Nutting C, Pitoia F, et al. Regional approaches to the management of patients with advanced, radioactive iodinerefractory differentiated thyroid carcinoma. Expert Rev Anticancer Ther (2012) 12(9):1137-47. doi:10.1586/era.12.96

4. Carvalho DP, Ferreira AC. The importance of sodium/iodide symporter (NIS) for thyroid cancer management. Arq Bras Endocrinol Metabol (2007) 51(5):672-82. doi:10.1590/S0004-27302007000500004

5. Adeniran AJ, Zhu Z, Gandhi M, Steward DL, Fidler JP, Giordano TJ, et al. Correlation between genetic alterations and microscopic features, clinical manifestations, and prognostic characteristics of thyroid papillary carcinomas. Am J Surg Pathol (2006) 30(2):216-22. doi:10.1097/01.pas.0000176432.73455.1b

6. Kimura ET, Nikiforova MN, Zhu Z, Knauf JA, Nikiforov YE, Fagin JA. High prevalence of BRAF mutations in thyroid cancer: genetic evidence for constitutive activation of the RET/PTC-RAS-BRAF signaling pathway in papillary thyroid carcinoma. Cancer Res (2003) 63(7):1454-7.

7. Soares P, Trovisco V, Rocha AS, Lima J, Castro P, Preto A, et al. BRAF mutations and RET/PTC rearrangements are alternative events in the etiopathogenesis of PTC. Oncogene (2003) 22(29):4578-80. doi:10.1038/sj.onc.1206706

8. Frattini M, Ferrario C, Bressan P, Balestra D, De Cecco L, Mondellini P, et al. Alternative mutations of BRAF, RET and NTRK1 are associated with similar but distinct gene expression patterns in papillary thyroid cancer. Oncogene (2004) 23(44):7436-40. doi:10.1038/si.onc.1207980

9. Nikiforova MN, Lynch RA, Biddinger PW, Alexander EK, Dorn GW II, Tallini G, et al. RAS point mutations and PAX8-PPAR gamma rearrangement in thyroid tumors: evidence for distinct molecular pathways in thyroid follicular carcinoma. J Clin Endocrinol Metab (2003) 88(5):2318-26. doi:10.1210/jc.2002-021907

10. Smallridge RC, Marlow LA, Copland JA. Anaplastic thyroid cancer: molecular pathogenesis and emerging therapies. Endocr Relat Cancer (2009) 16(1):17-44. doi:10.1677/ERC-08-0154

11. Xing M. Genetic alterations in the phosphatidylinositol-3 kinase/Akt pathway in thyroid cancer. Thyroid (2010) 20(7):697-706. doi:10.1089/thy.2010.1646

12. Ricarte-Filho JC, Ryder M, Chitale DA, Rivera M, Heguy A, Ladanyi M, et al. Mutational profile of advanced primary and metastatic radioactive iodine-refractory thyroid cancers reveals distinct pathogenetic roles for BRAF, PIK3CA, and AKT1. Cancer Res (2009) 69(11):4885-93. doi:10.1158/00085472.CAN-09-0727

13. Gauchotte G, Philippe C, Lacomme S, Leotard B, Wissler MP, Allou L, et al. BRAF, p53 and SOX2 in anaplastic thyroid carcinoma: evidence for multistep carcinogenesis. Pathology (2011) 43(5):447-52. doi:10.1097/PAT. 0b013e3283486178

14. Cassinelli G, Favini E, Degl'Innocenti D, Salvi A, De PG, Pierotti MA, et al. RET/PTC1-driven neoplastic transformation and proinvasive phenotype of human thyrocytes involve Met induction and beta-catenin nuclear translocation. Neoplasia (2009) 11(1):10-21.

15. Castellone MD, De FV, Rao DM, Bellelli R, Muthu M, Basolo F, et al. The betacatenin axis integrates multiple signals downstream from RET/papillary thyroid carcinoma leading to cell proliferation. Cancer Res (2009) 69(5):1867-76. doi:10.1158/0008-5472.CAN-08- 1982

16. Tartari CJ, Donadoni C, Manieri E, Mologni L, Mina PD, Villa A, et al. Dissection of the RET/beta-catenin interaction in the TPC1 thyroid cancer cell line. Am J Cancer Res (2011) 1(6):716-25.

17. Dohan O, Baloch Z, Banrevi Z, Livolsi V, Carrasco N. Rapid communication: predominant intracellular overexpression of the $\mathrm{Na}(+) / \mathrm{I}(-)$ symporter (NIS) in a large sampling of thyroid cancer cases. J Clin Endocrinol Metab (2001) 86(6):2697-700. doi:10.1210/jc.86.6.2697

18. Biondi B, Cooper DS. Benefits of thyrotropin suppression versus the risks of adverse effects in differentiated thyroid cancer. Thyroid (2010) 20(2):135-46. doi:10.1089/thy.2009.0311

19. Torrens JI, Burch HB. Serum thyroglobulin measurement. Utility in clinical practice. Endocrinol Metab Clin North Am (2001) 30(2):429-67. doi:10.1016/ S0889-8529(05)70194-8

20. Savin S, Cvejic D, Isic T, Paunovic I, Tatic S, Havelka M. The efficacy of the thyroid peroxidase marker for distinguishing follicular thyroid carcinoma from follicular adenoma. Exp Oncol (2006) 28(1):70-4. 
21. Gerard AC, Daumerie C, Mestdagh C, Gohy S, De Burbure C, Costagliola S, et al. Correlation between the loss of thyroglobulin iodination and the expression of thyroid-specific proteins involved in iodine metabolism in thyroid carcinomas. J Clin Endocrinol Metab (2003) 88(10):4977-83. doi:10.1210/jc. 2003-030586

22. Tanaka T, Umeki K, Yamamoto I, Sugiyama S, Noguchi S, Ohtaki S. Immunohistochemical loss of thyroid peroxidase in papillary thyroid carcinoma: strong suppression of peroxidase gene expression. J Pathol (1996) 179(1):89-94. doi:10.1002/(SICI)1096-9896(199605)179:1<89::AIDPATH546>3.0.CO;2-R

23. Savin S, Cvejic D, Isic T, Petrovic I, Paunovic I, Tatic S, et al. Thyroid peroxidase immunohistochemistry in differential diagnosis of thyroid tumors. Endocr Pathol (2006) 17(1):53-60. doi:10.1385/EP:17:1:53

24. Lazar V, Bidart JM, Caillou B, Mahe C, Lacroix L, Filetti S, et al. Expression of the $\mathrm{Na}+/ \mathrm{I}$ - symporter gene in human thyroid tumors: a comparison study with other thyroid-specific genes. J Clin Endocrinol Metab (1999) 84(9):3228-34. doi:10.1210/jcem.84.9.5996

25. Ward LS, Santarosa PL, Granja F, da Assumpcao LV, Savoldi M, Goldman GH. Low expression of sodium iodide symporter identifies aggressive thyroid tumors. Cancer Lett (2003) 200(1):85-91. doi:10.1016/S0304-3835(03) 00392-6

26. Sodre AK, Rubio IG, Galrao AL, Knobel M, Tomimori EK, Alves VA, et al. Association of low sodium-iodide symporter messenger ribonucleic acid expression in malignant thyroid nodules with increased intracellular protein staining. J Clin Endocrinol Metab (2008) 93(10):4141-5. doi:10.1210/jc.2007-0353

27. Wang ZF, Liu QJ, Liao SQ, Yang R, Ge T, He X, et al. Expression and correlation of sodium/iodide symporter and thyroid stimulating hormone receptor in human thyroid carcinoma. Tumori (2011) 97(4):540-6. doi:10.1700/950.10410

28. Tanaka K, Sonoo H, Yamamoto Y, Udagawa K, Kunisue H, Arime I, et al. Changes of expression level of the differentiation markers in papillary thyroid carcinoma under thyrotropin suppression therapy in vivo immunohistochemical detection of thyroglobulin, thyroid peroxidase, and thyrotropin receptor. J Surg Oncol (2000) 75(2):108-16. doi:10.1002/1096-9098(200010)75:2<108: :AID-JSO7>3.3.CO;2-M

29. Brabant G, Maenhaut C, Kohrle J, Scheumann G, Dralle H, Hoang-Vu C, et al. Human thyrotropin receptor gene: expression in thyroid tumors and correlation to markers of thyroid differentiation and dedifferentiation. Mol Cell Endocrinol (1991) 82(1):R7-12. doi:10.1016/0303-7207(91)90018-N

30. Kleiman DA, Buitrago D, Crowley MJ, Beninato T, Veach AJ, Zanzonico $\mathrm{PB}$, et al. Thyroid stimulating hormone increases iodine uptake by thyroid cancer cells during BRAF silencing. J Surg Res (2013) 182(1):85-93. doi:10.1016/j.jss.2012.08.053

31. Riesco-Eizaguirre G, Rodriguez I, De la Vieja A, Costamagna E, Carrasco $\mathrm{N}$, Nistal M, et al. The BRAFV600E oncogene induces transforming growth factor beta secretion leading to sodium iodide symporter repression and increased malignancy in thyroid cancer. Cancer Res (2009) 69(21):8317-25. doi:10.1158/0008-5472.CAN-09- 1248

32. Durante C, Puxeddu E, Ferretti E, Morisi R, Moretti S, Bruno R, et al. BRAF mutations in papillary thyroid carcinomas inhibit genes involved in iodine metabolism. J Clin Endocrinol Metab (2007) 92(7):2840-3. doi:10.1210/jc. 2006-2707

33. Oler G, Cerutti JM. High prevalence of BRAF mutation in a Brazilian cohort of patients with sporadic papillary thyroid carcinomas: correlation with more aggressive phenotype and decreased expression of iodide-metabolizing genes. Cancer (2009) 115(5):972-80. doi:10.1002/cncr.24118

34. Romei C, Ciampi R, Faviana P, Agate L, Molinaro E, Bottici V, et al. BRAFV600E mutation, but not RET/PTC rearrangements, is correlated with a lower expression of both thyroperoxidase and sodium iodide symporter genes in papillary thyroid cancer. Endocr Relat Cancer (2008) 15(2):511-20. doi:10.1677/ERC07-0130

35. de Souza EC, Padron AS, Braga WM, de Andrade BM, Vaisman M, Nasciutti LE, et al. MTOR downregulates iodide uptake in thyrocytes. J Endocrinol (2010) 206(1):113-20. doi:10.1677/JOE-09-0436

36. Pacini F, Schlumberger M, Dralle H, Elisei R, Smit JW, Wiersinga W. European consensus for the management of patients with differentiated thyroid carcinoma of the follicular epithelium. Eur J Endocrinol (2006) 154(6):787-803. doi:10.1530/eje.1.02158

37. Cooper DS, Doherty GM, Haugen BR, Kloos RT, Lee SL, Mandel SJ, et al. Revised American thyroid association management guidelines for patients with thyroid nodules and differentiated thyroid cancer. Thyroid (2009) 19(11):1167-214. doi:10.1089/thy.2009.0110

38. Schlumberger M, Catargi B, Borget I, Deandreis D, Zerdoud S, Bridji B, et al. Strategies of radioiodine ablation in patients with low-risk thyroid cancer. N Engl J Med (2012) 366(18):1663-73. doi:10.1056/NEJMoa1108586

39. Mallick U, Harmer C, Yap B, Wadsley J, Clarke S, Moss L, et al. Ablation with low-dose radioiodine and thyrotropin alfa in thyroid cancer. $N$ Engl J Med (2012) 366(18):1674-85. doi:10.1056/NEJMoa1109589

40. Schlumberger M, Tubiana M, De Vathaire F, Hill C, Gardet P, Travagli JP, et al. Long-term results of treatment of 283 patients with lung and bone metastases from differentiated thyroid carcinoma. J Clin Endocrinol Metab (1986) 63(4):960-7. doi:10.1210/jcem-63-4-960

41. Sabra MM, Dominguez JM, Grewal RK, Larson SM, Ghossein RA, Tuttle RM, et al. Clinical outcomes and molecular profile of differentiated thyroid cancers with radioiodine-avid distant metastases. J Clin Endocrinol Metab (2013) 98(5):E829-36. doi:10.1210/jc.2012-3933

42. Haugen BR. Management of the patient with progressive radioiodine nonresponsive disease. Semin Surg Oncol (1999) 16(1):34-41. doi:10.1002/(SICI) 1098-2388(199901/02)16:1<34::AID-SSU7>3.0.CO;2-2

43. Monchik JM, Donatini G, Iannuccilli J, Dupuy DE. Radiofrequency ablation and percutaneous ethanol injection treatment for recurrent local and distant well-differentiated thyroid carcinoma. Ann Surg (2006) 244(2):296-304. doi:10.1097/01.sla.0000217685.85467.2d

44. Vogl TJ, Lehnert T, Zangos S, Eichler K, Hammerstingl R, Korkusuz H, et al. Transpulmonary chemoembolization (TPCE) as a treatment for unresectable lung metastases. Eur Radiol (2008) 18(11):2449-55. doi:10.1007/s00330-0081056-0

45. Wood DE. Management of malignant tracheobronchial obstruction. Surg Clin North Am (2002) 82(3):621-42. doi:10.1016/S0039-6109(02)00025-7

46. Brose MS, Nutting CM, Jarzab B, Elisei R, Siena S, Bastholt L, et al. Sorafenib in radioactive iodine-refractory, locally advanced or metastatic differentiated thyroid cancer: a randomised, double-blind, phase 3 trial. Lancet (2014) 384(9940):319-28. doi:10.1016/S0140-6736(14)60421-9

47. Schlumberger M, Tahara M, Wirth L, Robinson B, Brose M, Elisei R. A phase 3, multicenter, double-blind, placebo-controlled trial of lenvatinib (E7080) in patients with 131I-refractory differentiated thyroid cancer (SELECT). J Clin Oncol (2014) 32(Suppl):LBA6008.

48. Glick D, Barth S, Macleod KF. Autophagy: cellular and molecular mechanisms. J Pathol (2010) 221(1):3-12. doi:10.1002/path.2697

49. Nakatogawa H, Suzuki K, Kamada Y, Ohsumi Y. Dynamics and diversity in autophagy mechanisms: lessons from yeast. Nat Rev Mol Cell Biol (2009) 10(7):458-67. doi:10.1038/nrm2708

50. Wullschleger S, Loewith R, Hall MN. TOR signaling in growth and metabolism. Cell (2006) 124(3):471-84. doi:10.1016/j.cell.2006.01.016

51. Sarbassov DD, Ali SM, Sabatini DM. Growing roles for the mTOR pathway. Curr Opin Cell Biol (2005) 17(6):596-603. doi:10.1016/j.ceb.2005.09.009

52. Gibbons JJ, Abraham RT, Yu K. Mammalian target of rapamycin: discovery of rapamycin reveals a signaling pathway important for normal and cancer cell growth. Semin Oncol (2009) 36(Suppl 3):S3-17. doi:10.1053/j.seminoncol. 2009.10.011

53. Souza EC, Ferreira AC, Carvalho DP. The mTOR protein as a target in thyroid cancer. Expert Opin Ther Targets (2011) 15(9):1099-112. doi:10.1517/ 14728222.2011.594044

54. Dewaele M, Maes H, Agostinis P. ROS-mediated mechanisms of autophagy stimulation and their relevance in cancer therapy. Autophagy (2010) 6(7):838-54. doi:10.4161/auto.6.7.12113

55. Mathew R, Karp CM, Beaudoin B, Vuong N, Chen G, Chen HY, et al. Autophagy suppresses tumorigenesis through elimination of p62. Cell (2009) 137(6):1062-75. doi:10.1016/j.cell.2009.03.048

56. Qu X, Yu J, Bhagat G, Furuya N, Hibshoosh H, Troxel A, et al. Promotion of tumorigenesis by heterozygous disruption of the beclin 1 autophagy gene. J Clin Invest (2003) 112(12):1809-20. doi:10.1172/JCI200320039

57. Miracco C, Cevenini G, Franchi A, Luzi P, Cosci E, Mourmouras V, et al. Beclin 1 and LC3 autophagic gene expression in cutaneous melanocytic lesions. Hum Pathol (2010) 41(4):503-12. doi:10.1016/j.humpath.2009.09.004

58. Cicchini M, Chakrabarti R, Kongara S, Price S, Nahar R, Lozy F, et al. Autophagy regulator BECN1 suppresses mammary tumorigenesis driven by WNT1 activation and following parity. Autophagy (2014) 10(11):2036-52. doi:10.4161/auto.34398 
59. Liang XH, Jackson S, Seaman M, Brown K, Kempkes B, Hibshoosh H, et al. Induction of autophagy and inhibition of tumorigenesis by beclin 1 . Nature (1999) 402(6762):672-6. doi:10.1038/45257

60. Zhao Y, Chen S, Gou WF, Xiao LJ, Takano Y, Zheng HC. Aberrant Beclin 1 expression is closely linked to carcinogenesis, differentiation, progression, and prognosis of ovarian epithelial carcinoma. Tumour Biol (2014) 35(3):1955-64. doi:10.1007/s13277-013-1261-6

61. Valente G, Morani F, Nicotra G, Fusco N, Peracchio C, Titone R, et al. Expression and clinical significance of the autophagy proteins BECLIN 1 and LC3 in ovarian cancer. Biomed Res Int (2014) 2014:462658. doi:10.1155/2014/ 462658

62. Yu M, Gou WF, Zhao S, Xiao LJ, Mao XY, Xing YN, et al. Beclin 1 expression is an independent prognostic factor for gastric carcinomas. Tumour Biol (2013) 34(2):1071-83. doi:10.1007/s13277-013-0648-8

63. Li X, Xu H, Ma H. Beclin 1 is highly expressed in papillary thyroid carcinoma and correlates with lymph node metastasis. Acta Chir Belg (2013) 113(3):175-81.

64. Maddodi N, Huang W, Havighurst T, Kim K, Longley BJ, Setaluri V. Induction of autophagy and inhibition of melanoma growth in vitro and in vivo by hyperactivation of oncogenic BRAF. J Invest Dermatol (2010) 130(6):1657-67. doi:10.1038/jid.2010.26

65. Kang R, Zeh HJ, Lotze MT, Tang D. The Beclin 1 network regulates autophagy and apoptosis. Cell Death Differ (2011) 18(4):571-80. doi:10.1038/ cdd.2010.191

66. Kang R, Tang D, Loze MT, Zeh HJ. Apoptosis to autophagy switch triggered by the MHC class III-encoded receptor for advanced glycation endproducts (RAGE). Autophagy (2011) 7(1):91-3. doi:10.1038/cdd.2009.149

67. Kang MR, Kim MS, Oh JE, Kim YR, Song SY, Kim SS, et al. Frameshift mutations of autophagy-related genes ATG2B, ATG5, ATG9B and ATG12 in gastric and colorectal cancers with microsatellite instability. J Pathol (2009) 217(5):702-6. doi:10.1002/path.2509

68. Kim MS, Jeong EG, Ahn CH, Kim SS, Lee SH, Yoo NJ. Frameshift mutation of UVRAG, an autophagy-related gene, in gastric carcinomas with microsatellite instability. Hum Pathol (2008) 39(7):1059-63. doi:10.1016/j.humpath. 2007.11.013

69. Poulogiannis G, McIntyre RE, Dimitriadi M, Apps JR, Wilson CH, Ichimura $\mathrm{K}$, et al. PARK2 deletions occur frequently in sporadic colorectal cancer and accelerate adenoma development in Apc mutant mice. Proc Natl Acad Sci U S A (2010) 107(34):15145-50. doi:10.1073/pnas.1009941107

70. Fujiwara M, Marusawa H, Wang HQ, Iwai A, Ikeuchi K, Imai Y, et al. Parkin as a tumor suppressor gene for hepatocellular carcinoma. Oncogene (2008) 27(46):6002-11. doi:10.1038/onc.2008.199

71. Plantinga TS, van de Vosse E, Huijbers A, Netea MG, Joosten LA, Smit JW, et al. Role of genetic variants of autophagy genes in susceptibility for nonmedullary thyroid cancer and patients outcome. PLoS One (2014) 9(4):e94086. doi:10.1371/journal.pone.0094086

72. Kundu M, Lindsten T, Yang CY, Wu J, Zhao F, Zhang J, et al. Ulkl plays a critical role in the autophagic clearance of mitochondria and ribosomes during reticulocyte maturation. Blood (2008) 112(4):1493-502. doi:10.1182/blood-2008$02-137398$

73. Sandoval H, Thiagarajan P, Dasgupta SK, Schumacher A, Prchal JT, Chen M, et al. Essential role for Nix in autophagic maturation of erythroid cells. Nature (2008) 454(7201):232-5. doi:10.1038/nature07006

74. Wei H, Wei S, Gan B, Peng X, Zou W, Guan JL. Suppression of autophagy by FIP200 deletion inhibits mammary tumorigenesis. Genes Dev (2011) 25(14):1510-27. doi:10.1101/gad.2051011

75. Pilarski R, Burt R, Kohlman W, Pho L, Shannon KM, Swisher E. Cowden syndrome and the PTEN hamartoma tumor syndrome: systematic review and revised diagnostic criteria. J Natl Cancer Inst (2013) 105(21):1607-16. doi:10.1093/jnci/djt277

76. Corazzari M, Rapino F, Ciccosanti F, Giglio P, Antonioli M, Conti B, et al. Oncogenic BRAF induces chronic ER stress condition resulting in increased basal autophagy and apoptotic resistance of cutaneous melanoma. Cell Death Differ (2014). doi:10.1038/cdd.2014.183

77. Wang Y, Guo Q, Zhao Y, Chen J, Wang S, Hu J, et al. BRAF-activated long non-coding RNA contributes to cell proliferation and activates autophagy in papillary thyroid carcinoma. Oncol Lett (2014) 8(5):1947-52. doi:10.3892/ol. 2014.2487
78. Ringel MD, Hayre N, Saito J, Saunier B, Schuppert F, Burch H, et al. Overexpression and overactivation of Akt in thyroid carcinoma. Cancer Res (2001) 61(16):6105-11.

79. Garcia-Rostan G, Costa AM, Pereira-Castro I, Salvatore G, Hernandez R, Hermsem MJ, et al. Mutation of the PIK3CA gene in anaplastic thyroid cancer. Cancer Res (2005) 65(22):10199-207. doi:10.1158/0008-5472.CAN-04-4259

80. Hou P, Liu D, Shan Y, Hu S, Studeman K, Condouris S, et al. Genetic alterations and their relationship in the phosphatidylinositol 3-kinase/Akt pathway in thyroid cancer. Clin Cancer Res (2007) 13(4):1161-70. doi:10.1158/10780432.CCR-06-1125

81. Liu Z, Hou P, Ji M, Guan H, Studeman K, Jensen K, et al. Highly prevalent genetic alterations in receptor tyrosine kinases and phosphatidylinositol 3-kinase/akt and mitogen-activated protein kinase pathways in anaplastic and follicular thyroid cancers. J Clin Endocrinol Metab (2008) 93(8):3106-16. doi:10.1210/jc.2008-0273

82. Hou P, Ji M, Xing M. Association of PTEN gene methylation with genetic alterations in the phosphatidylinositol 3-kinase/AKT signaling pathway in thyroid tumors. Cancer (2008) 113(9):2440-7. doi:10.1002/cncr.23869

83. Degenhardt K, Mathew R, Beaudoin B, Bray K, Anderson D, Chen G, et al. Autophagy promotes tumor cell survival and restricts necrosis, inflammation, and tumorigenesis. Cancer Cell (2006) 10(1):51-64. doi:10.1016/j.ccr. 2006.06.001

84. Li Y, Wang LX, Yang G, Hao F, Urba WJ, Hu HM. Efficient cross-presentation depends on autophagy in tumor cells. Cancer Res (2008) 68(17):6889-95. doi:10.1158/0008-5472.CAN-08-0161

85. Davalos AR, Coppe JP, Campisi J, Desprez PY. Senescent cells as a source of inflammatory factors for tumor progression. Cancer Metastasis Rev (2010) 29(2):273-83. doi:10.1007/s10555-010-9220-9

86. Bretz JD, Mezosi E, Giordano TJ, Gauger PG, Thompson NW, Baker JR Jr. Inflammatory cytokine regulation of TRAIL-mediated apoptosis in thyroid epithelial cells. Cell Death Differ (2002) 9(3):274-86. doi:10.1038/sj.cdd. 4400965

87. Mitsiades CS, Poulaki V, Mitsiades N. The role of apoptosis-inducing receptors of the tumor necrosis factor family in thyroid cancer. J Endocrinol (2003) 178(2):205-16. doi:10.1677/joe.0.1780205

88. Jin SM, Jang HW, Sohn SY, Kim NK, Joung JY, Cho YY, et al. Role of autophagy in the resistance to tumour necrosis factor-related apoptosis-inducing ligandinduced apoptosis in papillary and anaplastic thyroid cancer cells. Endocrine (2014) 45(2):256-62. doi:10.1007/s12020-013-9997-8

89. Pattingre S, Tassa A, Qu X, Garuti R, Liang XH, Mizushima N, et al. Bcl2 antiapoptotic proteins inhibit Beclin 1-dependent autophagy. Cell (2005) 122(6):927-39. doi:10.1016/j.cell.2005.07.002

90. Scott RC, Juhasz G, Neufeld TP. Direct induction of autophagy by Atg1 inhibits cell growth and induces apoptotic cell death. Curr Biol (2007) 17(1):1-11. doi:10.1016/j.cub.2006.10.053

91. Bursch W, Karwan A, Mayer M, Dornetshuber J, Frohwein U, Schulte-Hermann $\mathrm{R}$, et al. Cell death and autophagy: cytokines, drugs, and nutritional factors. Toxicology (2008) 254(3):147-57. doi:10.1016/j.tox.2008.07.048

92. Hua SC, Chang TC, Chen HR, Lu CH, Liu YW, Chen SH, et al. Reversine, a 2,6-disubstituted purine, as an anti-cancer agent in differentiated and undifferentiated thyroid cancer cells. Pharm Res (2012) 29(7):1990-2005. doi:10.1007/s11095-012-0727-3

93. Lu CH, Liu YW, Hua SC, Yu HI, Chang YP, Lee YR. Autophagy induction of reversine on human follicular thyroid cancer cells. Biomed Pharmacother (2012) 66(8):642-7. doi:10.1016/j.biopha.2012.08.001

94. Zeybek ND, Gulcelik NE, Kaymaz FF, Sarisozen C, Vural I, Bodur E, et al. Rosuvastatin induces apoptosis in cultured human papillary thyroid cancer cells. J Endocrinol (2011) 210(1):105-15. doi:10.1530/JOE-10-0411

95. Lopergolo A, Nicolini V, Favini E, Dal Bo L, Tortoreto M, Cominetti D, et al. Synergistic cooperation between sunitinib and cisplatin promotes apoptotic cell death in human medullary thyroid cancer. J Clin Endocrinol Metab (2014) 99(2):498-509. doi:10.1210/jc.2013-2574

96. Morani F, Phadngam S, Follo C, Titone R, Thongrakard V, Galetto A, et al. PTEN deficiency and mutant p53 confer glucose-addiction to thyroid cancer cells: impact of glucose depletion on cell proliferation, cell survival, autophagy and cell migration. Genes Cancer (2014) 5(7-8):226-39.

97. Akalay I, Janji B, Hasmim M, Noman MZ, Andre F, De Cremoux P, et al. Epithelial-to-mesenchymal transition and autophagy induction in breast 
carcinoma promote escape from T-cell-mediated lysis. Cancer Res (2013) 73(8):2418-27. doi:10.1158/0008-5472.CAN-12-2432

98. Fung C, Lock R, Gao S, Salas E, Debnath J. Induction of autophagy during extracellular matrix detachment promotes cell survival. Mol Biol Cell (2008) 19(3):797-806. doi:10.1091/mbc.E07-10-1092

99. Akalay I, Janji B, Hasmim M, Noman MZ, Thiery JP, Mami-Chouaib F, et al. EMT impairs breast carcinoma cell susceptibility to CTL-mediated lysis through autophagy induction. Autophagy (2013) 9(7):1104-6. doi:10.4161/ auto. 24728

100. Meng X, Kong DH, Li N, Zong ZH, Liu BQ, Du ZX, et al. Knockdown of BAG3 induces epithelial-mesenchymal transition in thyroid cancer cells through ZEB1 activation. Cell Death Dis (2014) 5:e1092. doi:10.1038/cddis.2014.32

101. Liu BQ, Du ZX, Zong ZH, Li C, Li N, Zhang Q, et al. BAG3-dependent noncanonical autophagy induced by proteasome inhibition in HepG2 cells. Autophagy (2013) 9(6):905-16. doi:10.4161/auto.24292

102. Li S, Zhang HY, Wang T, Meng X, Zong ZH, Kong DH, et al. BAG3 promoted starvation-induced apoptosis of thyroid cancer cells via attenuation of autophagy. J Clin Endocrinol Metab (2014) 99(11):E2298-307. doi:10.1210/jc. 2014- 1779

103. Guo Q, Zhao Y, Chen J, Hu J, Wang S, Zhang D, et al. BRAF-activated long noncoding RNA contributes to colorectal cancer migration by inducing epithelialmesenchymal transition. Oncol Lett (2014) 8(2):869-75. doi:10.3892/ol.2014. 2154

104. Li R, Zhang L, Jia L, Duan Y, Li Y, Bao L, et al. Long non-coding RNA BANCR promotes proliferation in malignant melanoma by regulating MAPK pathway activation. PLoS One (2014) 9(6):e100893. doi:10.1371/journal.pone. 0100893

105. Sun M, Liu XH, Wang KM, Nie FQ, Kong R, Yang JS, et al. Downregulation of BRAF activated non-coding RNA is associated with poor prognosis for non-small cell lung cancer and promotes metastasis by affecting epithelialmesenchymal transition. Mol Cancer (2014) 13:68. doi:10.1186/1476-459813-68

106. Chaachouay H, Ohneseit P, Toulany M, Kehlbach R, Multhoff G, Rodemann HP. Autophagy contributes to resistance of tumor cells to ionizing radiation. Radiother Oncol (2011) 99(3):287-92. doi:10.1016/j.radonc.2011.06.002

107. Mo N, Lu YK, Xie WM, Liu Y, Zhou WX, Wang HX, et al. Inhibition of autophagy enhances the radiosensitivity of nasopharyngeal carcinoma by reducing Rad51 expression. Oncol Rep (2014) 32(5):1905-12. doi:10.3892/or. 2014.3427

108. Wang P, Zhang L, Chen Z, Meng Z. MicroRNA targets autophagy in pancreatic cancer cells during cancer therapy. Autophagy (2013) 9(12):2171-2. doi:10.4161/auto. 26463

109. Wang P, Zhang J, Zhang L, Zhu Z, Fan J, Chen L, et al. MicroRNA 23b regulates autophagy associated with radioresistance of pancreatic cancer cells. Gastroenterology (2013) 145(5):1133-43 e12. doi:10.1053/j.gastro.2013.07.048

110. Lomonaco SL, Finniss S, Xiang C, Decarvalho A, Umansky F, Kalkanis SN, et al. The induction of autophagy by gamma-radiation contributes to the radioresistance of glioma stem cells. Int J Cancer (2009) 125(3):717-22. doi:10.1002/ijc.24402

111. Yeung SC, She M, Yang H, Pan J, Sun L, Chaplin D. Combination chemotherapy including combretastatin A4 phosphate and paclitaxel is effective against anaplastic thyroid cancer in a nude mouse xenograft model. J Clin Endocrinol Metab (2007) 92(8):2902-9. doi:10.1210/jc.2007-0027

112. Lin CI, Whang EE, Abramson MA, Jiang X, Price BD, Donner DB, et al. Autophagy: a new target for advanced papillary thyroid cancer therapy. Surgery (2009) 146(6):1208-14. doi:10.1016/j.surg.2009.09.019

113. Lin CI, Whang EE, Donner DB, Du J, Lorch J, He F, et al. Autophagy induction with RAD001 enhances chemosensitivity and radiosensitivity through Met inhibition in papillary thyroid cancer. Mol Cancer Res (2010) 8(9):1217-26. doi:10.1158/1541-7786.MCR-10-0162

114. Lin CI, Whang EE, Lorch JH, Ruan DT. Autophagic activation potentiates the antiproliferative effects of tyrosine kinase inhibitors in medullary thyroid cancer. Surgery (2012) 152(6):1142-9. doi:10.1016/j.surg.2012.08.016

115. Angell TE, Lechner MG, Jang JK, LoPresti JS, Epstein AL. MHC class I loss is a frequent mechanism of immune escape in papillary thyroid cancer that is reversed by interferon and selumetinib treatment in vitro. Clin Cancer Res (2014) 20(23):6034-44. doi:10.1158/1078-0432.CCR-14-0879

116. Michaud M, Martins I, Sukkurwala AQ, Adjemian S, Ma Y, Pellegatti $\mathrm{P}$, et al. Autophagy-dependent anticancer immune responses induced by chemotherapeutic agents in mice. Science (2011) 334(6062):1573-7. doi:10. 1126/science. 1208347

117. Lamark T, Johansen T. Autophagy: links with the proteasome. Curr Opin Cell Biol (2010) 22(2):192-8. doi:10.1016/j.ceb.2009.11.002

118. Zhang J, Wu P, Hu Y. Clinical and marketed proteasome inhibitors for cancer treatment. Curr Med Chem (2013) 20(20):2537-51. doi:10.2174/ 09298673113209990122

119. Yao F, Wang G, Wei W, Tu Y, Tong H, Sun S. An autophagy inhibitor enhances the inhibition of cell proliferation induced by a proteasome inhibitor in MCF-7 cells. Mol Med Rep (2012) 5(1):84-8. doi:10.3892/mmr.2011.590

120. Hui B, Shi YH, Ding ZB, Zhou J, Gu CY, Peng YF, et al. Proteasome inhibitor interacts synergistically with autophagy inhibitor to suppress proliferation and induce apoptosis in hepatocellular carcinoma. Cancer (2012) 118(22):5560-71. doi:10.1002/cncr.27586

121. Zhang X, Li W, Wang C, Leng X, Lian S, Feng J, et al. Inhibition of autophagy enhances apoptosis induced by proteasome inhibitor bortezomib in human glioblastoma U87 and U251 cells. Mol Cell Biochem (2014) 385(1-2):265-75. doi:10.1007/s11010-013-1835-Z

122. Zhang HY, Du ZX, Meng X, Zong ZH, Wang HQ. Beclin 1 enhances proteasome inhibition-mediated cytotoxicity of thyroid cancer cells in macroautophagyindependent manner. J Clin Endocrinol Metab (2013) 98(2):E217-26. doi:10. 1210/jc.2012-2679

123. Hombach-Klonisch S, Natarajan S, Thanasupawat T, Medapati M, Pathak A, Ghavami S, et al. Mechanisms of therapeutic resistance in cancer (stem) cells with emphasis on thyroid cancer cells. Front Endocrinol (Lausanne) (2014) 5:37. doi:10.3389/fendo.2014.00037

124. Guo Z, Hardin H, Lloyd RV. Cancer stem-like cells and thyroid cancer. Endocr Relat Cancer (2014) 21(5):T285-300. doi:10.1530/ERC-14-0002

125. Hinterseher U, Wunderlich A, Roth S, Ramaswamy A, Bartsch DK, Hauptmann $S$, et al. Expression of hedgehog signalling pathway in anaplastic thyroid cancer. Endocrine (2014) 45(3):439-47. doi:10.1007/s12020-013-0015-y

126. Bohinc B, Michelotti G, Diehl AM. Hedgehog signaling in human medullary thyroid carcinoma: a novel signaling pathway. Thyroid (2013) 23(9):1119-26. doi:10.1089/thy.2012.0474

127. Jimenez-Sanchez M, Menzies FM, Chang YY, Simecek N, Neufeld TP, Rubinsztein DC. The Hedgehog signalling pathway regulates autophagy. Nat Commun (2012) 3:1200. doi:10.1038/ncomms2212

128. Liu D, Hou P, Liu Z, Wu G, Xing M. Genetic alterations in the phosphoinositide 3-kinase/Akt signaling pathway confer sensitivity of thyroid cancer cells to therapeutic targeting of Akt and mammalian target of rapamycin. Cancer Res (2009) 69(18):7311-9. doi:10.1158/0008-5472.CAN-09-1077

129. Feng W, Jia S. Rapamycin inhibits the invasive ability of thyroid cancer cells by down-regulating the expression of VEGF-C in vitro. Cell Biochem Funct (2012) 30(6):487-91. doi:10.1002/cbf.2824

130. Papewalis C, Wuttke M, Schinner S, Willenberg HS, Baran AM, Scherbaum WA, et al. Role of the novel mTOR inhibitor RAD001 (everolimus) in anaplastic thyroid cancer. Horm Metab Res (2009) 41(10):752-6. doi:10.1055/s-00291224116

131. Malaguarnera R, Chen KY, Kim TY, Dominguez JM, Voza F, Ouyang B, et al. Switch in signaling control of mTORC1 activity after oncoprotein expression in thyroid cancer cell lines. J Clin Endocrinol Metab (2014) 99(10):E1976-87. doi:10.1210/jc.2013-3976

132. Motzer RJ, Escudier B, Oudard S, Hutson TE, Porta C, Bracarda S, et al. Phase 3 trial of everolimus for metastatic renal cell carcinoma: final results and analysis of prognostic factors. Cancer (2010) 116(18):4256-65. doi:10.1002/ cncr.25219

133. Rini BI, Atkins MB. Resistance to targeted therapy in renal-cell carcinoma. Lancet Oncol (2009) 10(10):992-1000. doi:10.1016/S14702045(09)70240-2

134. Zhou H, Huang S. The complexes of mammalian target of rapamycin. Curr Protein Pept Sci (2010) 11(6):409-24. doi:10.2174/138920310791824093

135. Schenone S, Brullo C, Musumeci F, Radi M, Botta M. ATP-competitive inhibitors of mTOR: an update. Curr Med Chem (2011) 18(20):2995-3014. doi:10.2174/092986711796391651

136. Gild ML, Landa I, Ryder M, Ghossein RA, Knauf JA, Fagin JA. Targeting mTOR in RET mutant medullary and differentiated thyroid cancer cells. Endocr Relat Cancer (2013) 20(5):659-67. doi:10.1530/ERC-13-0085

137. Ahmed M, Hussain AR, Bavi P, Ahmed SO, Al Sobhi SS, Al-Dayel F, et al. High prevalence of mTOR complex activity can be targeted using Torin2 in papillary 
thyroid carcinoma. Carcinogenesis (2014) 35(7):1564-72. doi:10.1093/carcin/ bgu051

138. Mandal M, Kim S, Younes MN, Jasser SA, El-Naggar AK, Mills GB, et al. The Akt inhibitor KP372-1 suppresses Akt activity and cell proliferation and induces apoptosis in thyroid cancer cells. Br J Cancer (2005) 92(10):1899-905. doi:10.1038/sj.bjc.6602595

139. Hu L, Hofmann J, Lu Y, Mills GB, Jaffe RB. Inhibition of phosphatidylinositol $3^{\prime}$-kinase increases efficacy of paclitaxel in in vitro and in vivo ovarian cancer models. Cancer Res (2002) 62(4):1087-92.

140. West KA, Castillo SS, Dennis PA. Activation of the PI3K/Akt pathway and chemotherapeutic resistance. Drug Resist Updat (2002) 5(6):234-48. doi:10. 1016/S1368-7646(02)00120-6

141. Liu R, Liu D, Trink E, Bojdani E, Ning G, Xing M. The Akt-specific inhibitor MK2206 selectively inhibits thyroid cancer cells harboring mutations that can activate the PI3K/Akt pathway. J Clin Endocrinol Metab (2011) 96(4):E577-85. doi:10.1210/jc.2010-2644

142. Cohen EE, Rosen LS, Vokes EE, Kies MS, Forastiere AA, Worden FP, et al. Axitinib is an active treatment for all histologic subtypes of advanced thyroid cancer: results from a phase II study. J Clin Oncol (2008) 26(29):4708-13. doi:10.1200/JCO.2007.15.9566

143. Ahmed M, Barbachano Y, Riddell A, Hickey J, Newbold KL, Viros A, et al. Analysis of the efficacy and toxicity of sorafenib in thyroid cancer: a phase II study in a UK based population. Eur J Endocrinol (2011) 165(2):315-22. doi:10.1530/EJE-11-0129

144. Sherman SI, Wirth LJ, Droz JP, Hofmann M, Bastholt L, Martins RG, et al. Motesanib diphosphate in progressive differentiated thyroid cancer. $N$ Engl J Med (2008) 359(1):31-42. doi:10.1056/NEJMoa075853

145. Bible KC, Suman VJ, Molina JR, Smallridge RC, Maples WJ, Menefee ME, et al. Efficacy of pazopanib in progressive, radioiodine-refractory, metastatic differentiated thyroid cancers: results of a phase 2 consortium study. Lancet Oncol (2010) 11(10):962-72. doi:10.1016/S1470-2045(10)70203-5

146. Lim SM, Chang H, Yoon MJ, Hong YK, Kim H, Chung WY, et al. A multicenter, phase II trial of everolimus in locally advanced or metastatic thyroid cancer of all histologic subtypes. Ann Oncol (2013) 24(12):3089-94. doi:10.1093/annonc/mdt379

147. Lorch J. A phase II study of everolimus in patients with aggressive RAI refractory (RAIR) thyroid cancer (TC). J Clin Oncol (2013) 31(Suppl):abstr6023.

148. Carracedo A, Ma L, Teruya-Feldstein J, Rojo F, Salmena L, Alimonti A, et al. Inhibition of mTORC1 leads to MAPK pathway activation through a PI3K-dependent feedback loop in human cancer. J Clin Invest (2008) 118(9):3065-74. doi:10.1172/JCI34739

149. Garraway LA, Janne PA. Circumventing cancer drug resistance in the era of personalized medicine. Cancer Discov (2012) 2(3):214-26. doi:10.1158/21598290.CD-12-0012

150. Wagle N, Grabiner BC, Van Allen EM, Amin-Mansour A, Taylor-Weiner A, Rosenberg $\mathrm{M}$, et al. Response and acquired resistance to everolimus in anaplastic thyroid cancer. N Engl J Med (2014) 371(15):1426-33. doi:10.1056/ NEJMoa1403352

151. Yang ZJ, Chee CE, Huang S, Sinicrope FA. The role of autophagy in cancer: therapeutic implications. Mol Cancer Ther (2011) 10(9):1533-41. doi:10.1158/ 1535-7163.MCT-11-0047

152. Janku F, McConkey DJ, Hong DS, Kurzrock R. Autophagy as a target for anticancer therapy. Nat Rev Clin Oncol (2011) 8(9):528-39. doi:10.1038/nrclinonc. 2011.71

153. Maira SM, Stauffer F, Brueggen J, Furet P, Schnell C, Fritsch C, et al. Identification and characterization of NVP-BEZ235, a new orally available dual phosphatidylinositol 3-kinase/mammalian target of rapamycin inhibitor with potent in vivo antitumor activity. Mol Cancer Ther (2008) 7(7):1851-63. doi:10.1158/1535-7163.MCT-08-0017
154. Lin SF, Huang YY, Lin JD, Chou TC, Hsueh C, Wong RJ. Utility of a $\mathrm{PI} 3 \mathrm{~K} / \mathrm{mTOR}$ inhibitor (NVP-BEZ235) for thyroid cancer therapy. PLoS One (2012) 7(10):e46726. doi:10.1371/journal.pone.0046726

155. Jin N, Jiang T, Rosen DM, Nelkin BD, Ball DW. Dual inhibition of mitogenactivated protein kinase kinase and mammalian target of rapamycin in differentiated and anaplastic thyroid cancer. J Clin Endocrinol Metab (2009) 94(10):4107-12. doi:10.1210/jc.2009-0662

156. Kandil E, Tsumagari K, Ma J, Abd Elmageed ZY, Li X, Slakey D, et al. Synergistic inhibition of thyroid cancer by suppressing MAPK/PI3K/AKT pathways. J Surg Res (2013) 184(2):898-906. doi:10.1016/j.jss.2013.03.052

157. Jin N, Jiang T, Rosen DM, Nelkin BD, Ball DW. Synergistic action of a RAF inhibitor and a dual PI3K/mTOR inhibitor in thyroid cancer. Clin Cancer Res (2011) 17(20):6482-9. doi:10.1158/1078-0432.CCR-11-0933

158. Sherman EJ, Ho AL, Fury MG, Baxi SS, Haque S, Lipson BL, et al. Phase II study of everolimus and sorafenib for the treatment of metastatic thyroid cancer. J Clin Oncol (2013) 31(Suppl):abstr6024.

159. Fan QW, Cheng C, Hackett C, Feldman M, Houseman BT, Nicolaides T, et al. Akt and autophagy cooperate to promote survival of drug-resistant glioma. Sci Signal (2010) 3(147):ra81. doi:10.1126/scisignal.2001017

160. Plantinga TS, Heinhuis B, Gerrits D, Netea MG, Joosten LA, Hermus AR, et al. mTOR Inhibition promotes TTF1-dependent redifferentiation and restores iodine uptake in thyroid carcinoma cell lines. J Clin Endocrinol Metab (2014) 99(7):E1368-75. doi:10.1210/jc.2014-1171

161. Fury MG, Sherman E, Haque S, Korte S, Lisa D, Shen R, et al. A phase I study of daily everolimus plus low-dose weekly cisplatin for patients with advanced solid tumors. Cancer Chemother Pharmacol (2012) 69(3):591-8. doi:10.1007/s00280-011-1734-5

162. Kogai T, Sajid-Crockett S, Newmarch LS, Liu YY, Brent GA. Phosphoinositide3-kinase inhibition induces sodium/iodide symporter expression in rat thyroid cells and human papillary thyroid cancer cells. J Endocrinol (2008) 199(2):243-52. doi:10.1677/JOE-08-0333

163. Ho AL, Grewal RK, Leboeuf R, Sherman EJ, Pfister DG, Deandreis D, et al. Selumetinib-enhanced radioiodine uptake in advanced thyroid cancer. $N$ Engl J Med (2013) 368(7):623-32. doi:10.1056/NEJMoa1209288

164. Von Hoff DD, Stephenson JJ Jr, Rosen P, Loesch DM, Borad MJ, Anthony S, et al. Pilot study using molecular profiling of patients' tumors to find potential targets and select treatments for their refractory cancers. J Clin Oncol (2010) 28(33):4877-83. doi:10.1200/JCO.2009.26.5983

165. Roychowdhury S, Iyer MK, Robinson DR, Lonigro RJ, Wu YM, Cao X, et al. Personalized oncology through integrative high-throughput sequencing: a pilot study. Sci Transl Med (2011) 3(111):111ra21. doi:10.1126/scitranslmed. 3003161

Conflict of Interest Statement: The authors declare that the research was conducted in the absence of any commercial or financial relationships that could be construed as a potential conflict of interest.

Received: 26 December 2014; accepted: 05 February 2015; published online: 18 February 2015.

Citation: Netea-Maier RT, Klück V, Plantinga TS and Smit JWA (2015) Autophagy in thyroid cancer: present knowledge and future perspectives. Front. Endocrinol. 6:22. doi: $10.3389 /$ fendo.2015.00022

This article was submitted to Cancer Endocrinology, a section of the journal Frontiers in Endocrinology.

Copyright (ㄷ 2015 Netea-Maier, Klück, Plantinga and Smit. This is an open-access article distributed under the terms of the Creative Commons Attribution License (CC BY). The use, distribution or reproduction in other forums is permitted, provided the original author(s) or licensor are credited and that the original publication in this journal is cited, in accordance with accepted academic practice. No use, distribution or reproduction is permitted which does not comply with these terms. 